\title{
Ankle Osteoarthritis and Arthroplasty
}

\author{
Nadr M. Jomha, Angela Scharfenberger, \\ Gordon Goplen and M. Elizabeth Pedersen \\ Additional information is available at the end of the chapter \\ http://dx.doi.org/10.5772/54224
}

\section{Introduction}

The World Health Organization estimates that $10 \%$ of the world's population over the age of 60 suffers from osteoarthritis (OA) [1]. The majority of these cases involve the hip and knee. Symptomatic osteoarthritis of the ankle with radiographic changes is seen in approximately $11 \%$ of patients seeking treatment for "arthritis" [1]. Idiopathic arthritis, as seen in the hip and knee, is rare in the ankle joint. The majority of ankle arthritis is secondary to trauma (70\%), with a smaller percentage being attributed to inflammatory arthropathies such as RA (12\%) and only $7 \%$ attributed to primary OA [2]. Ankle arthritis can be a debilitating disease. In fact, the mental and physical disability associated with end-stage arthritis of the ankle is at least as severe as that associated with end stage hip arthritis [3].

\subsection{Anatomy}

The ankle joint consists of the tibio-talar joint incorporating articular surfaces between the talar dome with the tibial plafond, and the medial talus with the medial malleolus. In addition, there is an articulation between the lateral talus with the lateral malleolus. It is mainly a rolling joint with congruent surfaces at high loads, allowing it to withstand large pressures [1]. The ankle carries 5 times body weight during normal walking activities [4]. The majority of the load $(75 \%)$ is distributed across the tibio-talar joint but some force is transmitted through the medial and lateral sides [5]. Pathological conditions such as a mal-united ankle fracture results in changes in the contact stresses and the overall contact area [5].

\subsection{History}

Patients with arthritic changes to the ankle have the typical "arthritic" complaints as seen in other affected joints. Patients often present with pain, swelling and stiffness. The pain may 
be worse with weight bearing/impact activities, with weather changes, and may wake them at night. Painful symptoms may be worse with initiation of activities (especially first thing in the morning) but may improve during the activity. The pain usually intensifies with prolonged activity and after the activity is completed. Stiffness can be present, usually worse first thing in the morning or after a prolonged rest. Swelling can be particularly bothersome and is usually intermittent. Patients complain of pain in the anterior talo-crural area and have difficulty with reciprocal stair climbing and hills. Subfibular or lateral foot pain is not common and is more typical for patients with subtalar arthritis which may be seen in combination with ankle arthritis. Patients with subtalar arthritis complain of difficulties with walking on uneven ground.

Given that most ankle arthritis is post-traumatic, a history of previous trauma should be determined including a history of severe or repetitive ankle sprains [6]. History of previous infection is important to ascertain as it can be a contraindication to joint arthroplasty and current infection should be treated immediately with antibiotics and possibly debridement. Systemic illness such as rheumatoid arthritis, gout, and hemophilia should be noted. Patients with diabetes mellitus can present with Charcot deformity including arthritis.

\subsection{Physical exam}

Patients should be inspected for general lower limb alignment, including the knees, ankle, hindfoot, midfoot and forefoot, paying particular attention to varus/valgus mal-alignment of the hindfoot and dorsiflexion/plantarflexion mal-alignment of the ankle. Inspection should note any swelling about the ankle, wasting of the calf musculature and previous surgical incisions. Gait should be observed. Patients generally have a foreshortened stance phase, and may walk with their foot externally rotated. Patients with ankle arthritis walk with a shorter stride length, reduced walking speed, and a shorter stance phase of the affected limb $[4,5,7$, 8]. Active and passive range of motion should be compared to the other side for ankle dorsi/ plantar flexion and subtalar eversion/inversion. In severe ankle arthritis, it is important to differentiate range of motion coming from the ankle joint as opposed to the hindfoot and midfoot joints. Heel eversion and inversion may also show restrictions of movement. Palpation should include all bone prominences and the anterior margin of the ankle joint looking for areas of tenderness or synovitis. Sensory changes or motor dysfunction should be noted for possible neurological abnormalities. Both dorsalis pedis and posterior tibial pulses should be assessed along with capillary refill and any abnormalities may require further vascular investigations with $\mathrm{ABI}$ and/or $\mathrm{CT}$ angiogram.

\subsection{Imaging}

Standard radiographs should include WEIGHTBEARING AP/Lateral and mortise views of both ankles, and AP and lateral views of the foot. Radiographs can be reviewed for the classic signs of OA including loss of joint space, subchondral sclerosis, cyst formation and osteophyte formation. CT scan can be useful to determine arthritic changes in adjacent joints, or to look at the surrounding bone stock when considering arthroplasty but this technique is compromised for diagnosing early OA with cartilage loss because it is not done in the 
weightbearing position; therefore it can be misleading regarding joint space maintenance and overall joint alignment. MRI is not required when assessing ankle arthritis. If there is a past history of infection, quiescent infection should be ruled out with a bone/gallium scan combination or a white blood cell scan.

\section{Conservative treatment}

\subsection{Medications}

Non-steroidal anti-inflammatories drugs (NSAIDs) have long been the mainstay for symptomatic treatment of arthritic joint pain. These drugs control the pain of arthritis but are not disease modifying agents. Current classes of drugs include standard NSAIDs (eg. Ibuprofen, Naproxen, Indomethacin). The newer Cox 2 inhibitors [eg. Celecoxib (Celebrex) and Rofecoxib (Vioxx)] have less gastrointestinal side effects [9, 10]; however, concern about higher risks of myocardial infarction, thrombosis and stroke lead to withdrawl of Rofecoxib (Vioxx) from the market in 2004 Patients with long term NSAID use are counseled to have blood pressure and kidney function checked regularly with their family physicians as all NSAIDS still put patients at risk for renal-related complications.

Nutraceuticals such as glucosamine sulphate and chondroitin sulphate are popular non-prescription remedies. There have been a multiple studies on these products, the vast majority done in the arthritic knee population. Findings include pain modification similar to NSAIDS with a similar side effect profile, although the onset is slower [11,12]. Other studies suggest actual disease modification with long term glucosamine use, as seen by NON progression of joint space narrowing [13, 14]. More recent authors have found no difference between glucosamine and placebo [15] and no evidence of disease modification or pain relief [16]. Popular dosing for glucosamine is 1.5 grams per day.

\subsection{Injections}

Corticosteroids demonstrate both anti-inflammatory response and immunosuppressive effect. After intra-articular administration, there is a decrease in erythema, swelling, heat and tenderness. This may be secondary to altered movement and function of leucocytes, reduced micro vascular dilation and permeability, and reduced prostaglandin synthesis. Side effects can include septic arthritis, tendon rupture, post injection wheal and flare, facial flushing, atrophic skin changes, toxic effect on cartilage (at large doses) and possible systemic absorption. Standard limit of injections in weight bearing joints is 3-4 injections per year [17].

Hyaluronic acid (HA) is a major component of synovial fluid, and comprises part of the structure of hyaline cartilage. Viscosupplementation by injection of HA derivatives (as available in pharmaceutical components) has multiple proposed mechanisms of action. Biologic effects include an anti-inflammatory as well as anti-oxidant effect, and restoration of endogenous synthesis via positive feedback loop. Viscoelastic properties include a "mechanical spongy" trapping of immune complexes and inflammatory cells and restoration of synovial 
fluid viscosity and elasticity. Multiple versions of HA exist from multiple pharmaceutical companies. Not all are available in all countries [18]. Some examples of currently available products include Hyalgan (sodium hyaluronate; Sanofi-Aventis, Bridgewater, NJ, USA), Synvisc (hylan GF-20; Genzyme Corportation, Cambridge, MA, USA), Supartz (sodium hyaluronate; Smith \& Nephew, London, UK), Orthovisc (high molecular weight hyaluronan; Anika Therapeutics, Inc., Bedford, MA, USA), Euflexxa (1\% sodium hyaluronate; Ferring Pharmaceuticals, Inc., Saint-Prex, Switzerland), and Durolane (stabilize hyaluronic acid; Smith \& Nephew, York, UK). Most require multiple injections although newer ones (eg Durolane) are coming to market that require only one injection. Side effect of HA injections are rare but include anaphylaxis, pseudogout type reaction, and Severe Acute Inflammatory Reaction (SAIR) which presents like septic arthritis.

The effectiveness of hyaluronic acid derivatives in the ankle joint has not been determined due to poorly conducted studies with mixed results from the few good studies performed $[19,20]$ although a recent randomized control trial article comparing HA to saline in the ankle showed no therapeutic benefit from the HA injection. Both HA and Saline injection resulted in similar changes in VAS, AOS and AOFAS scores [21]. Further high quality studies need to be completed before a definitive recommendation for HA derivatives in the ankle can be given.

\subsection{Bracing}

There is a paucity of any literature on bracing and shoe modifications. Practically, bracing progresses from a simple lace-up ankle brace to a more elaborate rigid Ankle Foot Orthosis (AFO) (Figure 1). A rigid AFO works by restricting painful ankle range of motion.

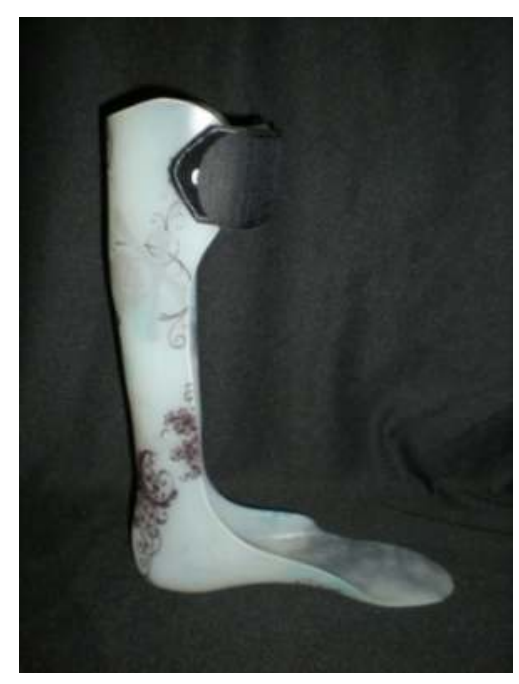

Figure 1. Photograph of a rigid AFO. 
More severely affected joints may be helped by a clamshell AFO (offloading AFO) (Figure 2). This type of orthosis works by transferring weight from the ankle to the calf using the clamshell portion that wraps around the calf (similar in principle to a patellar-tendon brace). This type of AFO can have a hinge to maintain ankle range of motion or can be rigid to restrict motion as well as off-load the joint.
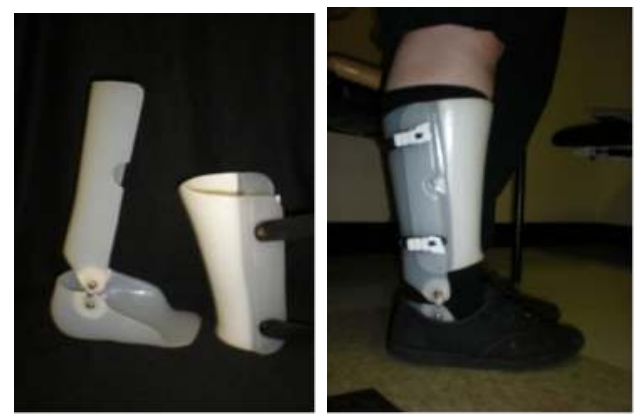

Figure 2. Offloading AFO with a hinge. Picture on the left demonstrates the AFO in a separated condition while the right picture shows it applied to the patient.

Some patients may benefit from shoe modifications such as a rocker bottom shoe (Figure 3). This provides increased toe-off, thereby stressing the ankle joint less.

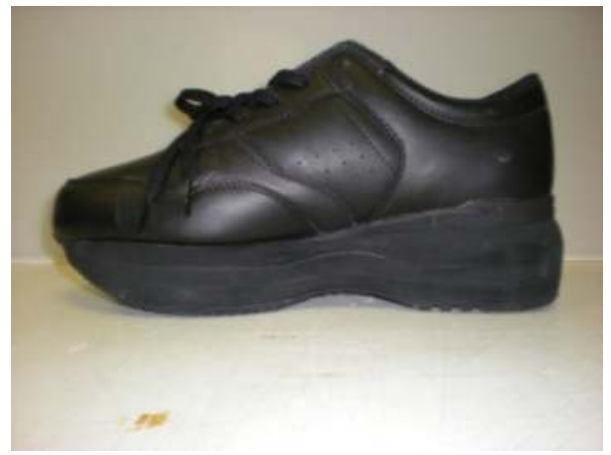

Figure 3. Forefoot rocker bottom shoe.

\section{Surgical options}

After non-operative treatments have been exhausted, surgical treatments can be considered. These options will depend on the location and extent of the arthritis. 


\subsection{Focal joint abnormalities}

Localized lesions within the ankle joint can progress to generalized osteoarthritis. As documented in the knee, larger lesions have a worse prognosis than smaller lesions [22, 23]. Smaller lesions (usually considered $1 \mathrm{~cm}^{2}$ or less can be asymptomatic or often are dealt with by arthroscopic debridement of loose cartilage with or without microfracture technique. If there is underlying bone necrosis, removal of this bone and overlying damaged cartilage can provide symptomatic relief. For larger lesions, the surgical options become more complicated and less predictable. There are a variety of techniques that can be used but no specific technique has been shown to superior to the rest. The most basic and economical procedure is microfacture. This technique can be used to induce local mesenchymal stem cells to influx to the defect and produce a fibrocartilage repair surface that can function well, particularly in the short to medium term [24, 25],. Although most research has been performed in the knee, this can be successful in the ankle as well [26, 27]. Of the more complicated procedures, perhaps the most publicized is autologous chondrocyte implantation (ACI) first described in 1994 in the knee [28]. It is also performed in the ankle [29]. Although there is a lot of literature published on this technique in the knee, the inability to reproduce the complex nature of the articular matrix has led to further investigation into variations of the technique including matrix-associated chondrocyte implantation (MACI) [30,31] and characterized chondrocyte implantation (CCI) [32]. Both of these techniques attempt to improve on the quality of matrix formed during the procedure. Other techniques utilize intact matrix to replace damaged matrix. This ensures the complex structure of the matrix is maintained. These techniques include osteochondral autograft transplantation (OATS) [33, 34] and mosaicplasty [35]) [36, 37], and bulk osteochondral allografts [38-41]. Finally, other more experimental techniques such as synthetic scaffolds and mesenchymal stem cells have been tried with variable success [42-45].

\subsubsection{Cell-based techniques}

Microfracture - Microfracture is a well-established technique for full thickness cartilage defects with an intact subchondral bone plate. The cartilage is debrided to form a well-contained defect with stable margins. The underlying bone is perforated with a sharp awl or pick at 3-4mm intervals while ensuring a stable subchondral plate remains intact to support the incoming cells. The perforations should penetrate deep enough to allow mesenchymal stem cells from the underlying spongy bone to enter the defect. The blood that emerges from the bone forms a clot and the stem cells differentiate into chondrocytes and fibrochondrocytes to produce a fibrocartilage that fills the defects.

Post-operatively, the patient is allowed early ROM but should be non-weight bearing for a period of time to allow some tissue formation. The length of time depends on the size and location of the lesion. Advantages of this technique include that it is one operation with low cost. Disadvantages include that fibrocartilage instead of hyaline cartilage is formed, filling of the defect is unpredictable and often incomplete [46]. That said, if good results can be obtained, the results in the ankle may not deteriorate over time [27]. This is considered a first line treatment by many surgeons, especially those that do not have access to the more complicated and expensive exogenous cell- or tissue-based therapies. 
Autologous Chondrocyte Implantation (ACI and its analogues) - ACI is the most publicized technique for repairing/regenerating pure cartilage defects in the knee joint. First popularized by Brittberg in 1994 [28], thousands of patients have been treated using this technique in the knee joint but far fewer in the ankle joint. Studies in the ankle have reported good intermediate- and long-term results [47, 48]. Despite the historical background and extensive use, the technique has been modified to incorporate a matrix (MACI) or utilizing specific chondrocytes from the harvest (CCI) in an attempt to improve results. This suggests that the results from ACI are not optimal. ACI is a complicated technique that entails removing a portion of cartilage from a relative non-weight bearing portion of the joint and sending it to a lab for processing. Typically the donor cartilage is harvested from the ipsilateral knee joint $[47,48]$. The ankle joint is typically not used as no specific safe area has been clearly defined [49]. During processing, the cells are removed from the matrix and expanded up to 20 million cells over a period of 3-4 weeks. The cells are then re-implanted at a second surgical procedure. This entails opening the joint, preparing the defect by making sure it has welldefined margins with an intact subchondral plate to prevent the intrusion of mesenchymal stem cells from the bone. A periosteal flap is harvested from a nearby area and sutured over the defect leaving a small area for injection of the expanded cells. The cells are injected under that flap that is then closed and sealed with fibrin glue. Often, a malleolar osteotomy is required to gain access to areas of the talar dome.

MACI is the next generation of ACI that incorporates the use of a scaffold [50-52]. The procedure is similar to that of ACI except that a matrix is used instead of a periosteal flap. The matrix is impregnated with the cells and shaped to the size of the defect. It is inserted and fixed by different mechanisms. Advantages of this technique include that it can be done arthroscopically in some cases and does not require the extra step of harvesting and suturing the periosteal flap. Thus it is less invasive. It has not been shown to be conclusively better than ACI. CCI (characterized chondrocyte implantation) is almost exactly the same as ACI except that the laboratory preselects specific cells that the company believes are predisposed to form articular cartilage out of all those that are harvested. These are the cells that are then expanded and re-implanted with the theory that the identified subpopulation of chondrocytes will produce a more physiologically intact matrix. The disadvantage of this technique is some patients do not have sufficient cells that meet the criteria for an enhanced population and, therefore, are not candidates for this procedure.

The results for these procedures have generally been good. Concerns with these procedures include that two separate surgical procedures are required and the cell processing can be prohibitively expensive. These major concerns limit their availability, especially when they have not been conclusively shown to be superior to other techniques [53]. The uncertainties of these techniques have led some researchers to investigate the use of mesenchymal stem cells instead of chondrocytes. This would allow the surgery to be completed at one time and may produce young chondrocytes that could potentially produce a more robust cartilage. These techniques are in the more experimental stage and more commonly used in the knee joint. 


\subsubsection{Tissue-based techniques}

Osteochondral autograft transplantation is a technique developed for small to medium sized defects. It consists of harvesting osteochondral plugs from less weight bearing portions of the same joint (or a different joint such as the knee when dealing with the ankle) and implanting them into the defect. This is accomplished by using $6 \mathrm{~mm}$ diameter reamers to a depth of 10-15mm into the subchondal bone. A corresponding osteochondral core is harvested from another area and gently impacted into the newly formed defect attempting to achieve a press-fit while maintaining the contour of the articular surface. With lesions larger than $6 \mathrm{~mm}$ diameter (ie most lesions that require treatment), multiple cores are required and press-fit with an interdigitating method and termed mosaicplasty. Once again, there are some reported good results using this technique [33, 36, 37, 54] but this is a complicated technique with multiple drawbacks. Harvesting cores from the ankle is usually not possible, therefore another joint must be violated and the harvest sites are not without possible complications such as knee pain and instability $[35,55]$. Typically an osteotomy is required to gain access to the talar dome because the plugs must be inserted perpendicular to the surface of the joint. Alignment of the multiple plugs is difficult to ensure a smooth surface and the cartilage from the harvest often is of different thickness compared to the insertion site resulting in a variable underlying subchondral bone. Obtaining precise contour matching for lesions on the "shoulder" of the talus can be extremely difficult. Bone plugs of only $6 \mathrm{~mm}$ diameter are susceptible to fracture resulting in unstable fixation and the boundary between the transplanted cartilage and native cartilage heals with fibrocartilage.

Osteochondral allografts can be done orthotopically and can be used for partial or whole joint replacement procedures. Popularized by Gross in the 1970's, these allografts were typically fresh and used for all types of defects in many joints including those defects due to tumours and trauma. Historically, these grafts were used in defects that consisted of bone and cartilage but can be used for cartilage-only defects as well. Good to excellent medium- and long-term results have been reported [38-41,56] but the use of this technique became restricted as concerns regarding transmission of infectious diseases became more prevalent. Considering that this is not a life threatening disorder, the risk of transmission of infectious diseases does not seem warranted (although disease transmission has been very rarely reported) and this method is rarely used. To decrease the risk by allowing more time for testing, hypothermic storage at $4^{\circ} \mathrm{C}$ was developed and allows the tissues to be stored for 28-42 days prior to transplantation. Unfortunately, cellular deterioration tends to begin after 7-14 days $[57,58]$. Given that regulatory clearance takes about 14 days, the viability of the cells within the tissue may not be as healthy as those in fresh allograft or in autograft. Investigations have been ongoing to develop storage techniques that eliminate the possibility of infectious disease transmission and tissue deterioration over time while enabling the creation of a large tissue bank for ready access. Recently we have developed a cryopreservation technique that can store the tissue indefinitely without deterioration and this may improve access to the tissue required for this technique [59]. Despite the limitations of hypothermic storage, there has been a resurgence of osteochondral allografting in recent years. This is the only biologic technique that can resurface whole joints $[60,61]$ and has been quite successful for 
partial joint replacements [40, 62]. Bugbee et al [60] have published promising results in total ankle arthroplasty using osteochondral allografts and similar procedures have been performed in Europe [61] but further improvements are required.

\subsection{Early osteoarthritic changes}

Once osteoarthritic changes become evident, cell based cartilage resurfacing techniques become less relevant due to the generalized nature of the process. There are some surgical techniques that can be used to palliate symptoms depending on the location and severity of the arthritis.

Exostectomies - Occasionally impingement symptoms can be a significant component of arthritis pain. This usually occurs with anterior osteophytes off the distal tibia or talar neck. Occasionally these osteophytes can form around the malleoli. When impingement pain is a prominent feature, removal of the osteophytes, either open or arthroscopically, can be performed with significant improvement of symptoms. The exostectomy can include only the osteophytes itself or also part of the arthritic articular surface leaving only healthier cartilage tissue (Figure 4).

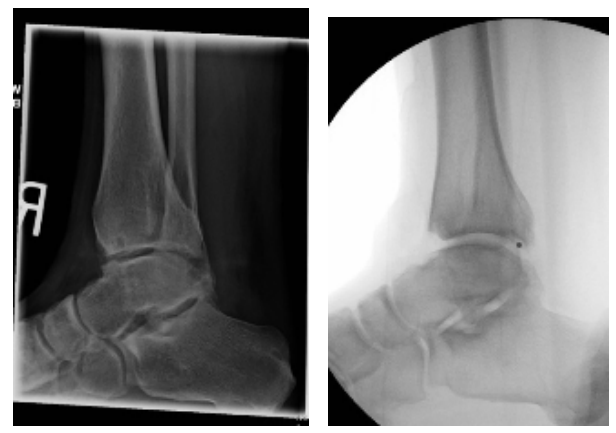

Figure 4. Left image shows preoperative lateral radiograph demonstrating anterior tibial and talar neck osteophytes. Right image shows intraoperative fluoroscopic image after anterior tibial and talar neck exostectomies.

Osteotomies - Occasionally the osteoarthritis is more severe in one portion of the joint. This is often medial or lateral. Offloading the arthritic portion of the joint with a closing (Figure 5), opening wedge osteotomy (Figure 6) or a dome osteotomy (Figure 7) can also provide some symptomatic relief [63-65]. 
Distraction arthroplasty - Recently, some investigation has gone into determining the effect of distraction arthroplasty. Joint distraction using an external fixator can alter the internal joint environment and possibly improve joint function. Early results are promising, even with more advanced osteoarthritis, but much more work needs to be completed [66].

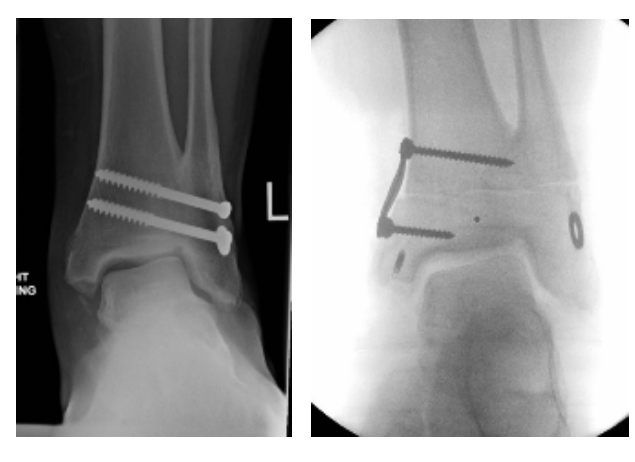

Figure 5. Radiographic images of medial closing wedge osteotomy after a distal tibial-fibular fusion resulted in lateral joint overload. Right image is an intraoperative fluoroscopic view after fixation with a compression staple.
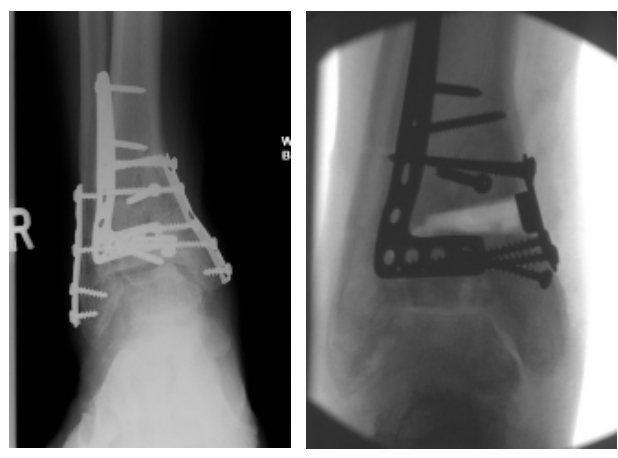

Figure 6. Radiographic images of a medial opening wedge osteotomy after open reduction and internal fixation resulted in a varus malunion. The distal screws were removed from the original plate and an opening wedge osteotomy was performed using an interposition plate. 


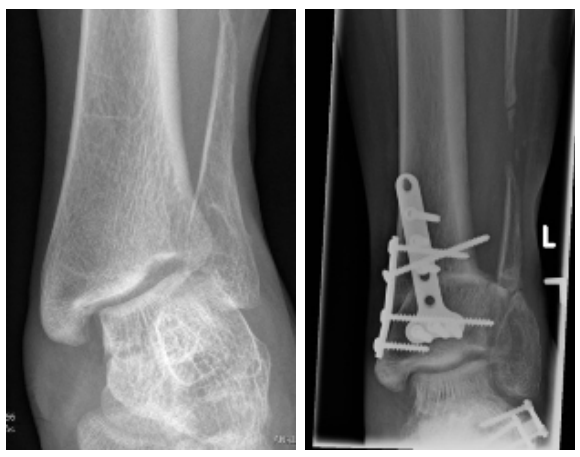

Figure 7. Dome osteotomy of the distal tibia. Original radiograph show severe valgus malunion due to a growth arrest after an open fracture as a child. The dome osteotomy was performed to incorporate the tibia and fibula and rotate the joint as a whole. Medial joint has been fully corrected while the lateral joint remains elevated due to intraarticular incongruity.

\subsection{Global osteoarthritis}

Once the osteoarthritis becomes global and more severe, the treatment options become more limited. The mainstay of treatment for end-stage ankle arthritis is ankle fusion although synthetic total joint arthroplasty is becoming more common as will be discussed. In addition, total ankle arthroplasty allografting is an experimental technique that has recently been developed that may be used in select cases.

Ankle fusion is the mainstay treatment for end-stage ankle arthritis. It has been performed for over 130 years [67] and there are research stucies that demonstrate the longterm effectiveness $[68,69]$. Complications of ankle fusion include nonunion, malunion, infection, nerve injury, persisting pain, loss of ankle range of motion, limp, and arthritis of surrounding joints due to overload [70, 71]. Ankle fusion entails removing all of the remaining articular cartilage from the joint as well as the underlying subchondral bone leaving exposed cancellous bone. The surfaces are shaped so that there is excellent contact between the talar dome and the tibial plafond. Most techniques incorporate the medial malleolus as a medial buttress while some also include the lateral malleolus. Once the surfaces are prepared, internal fixation (occasionally external fixation) is applied. Postoperative splinting in either an aircast or plaster cast is employed for 6-12 weeks with nonweight bearing from 1-12 weeks depending on bone quality and rigidity of fixation and progression of fusion radiographically.

Over the years, many techniques have been described with increasing success with regards to fusion rates. Successful fusion rates can be expected to range from $86-100 \%$ depending on patient characteristics and surgical techniques [68, 72-83]. The most commonly used techniques utilize internal fixation. This can be completed using anterior, lateral or posterior approaches. Fixation can be achieved using crossed screws, plate and screws or an intramedullary nail. Another more recent method includes the joint debridement achieved 
arthroscopically with percutaneous screw fixation. Alternatively, external fixation using standard external fixation techniques or Ilizarov can be used after open joint debridement.

Traditionally, open techniques using an anterior approach going either medial or just lateral to the tibialis anterior tendon have been used. This approach typically provides access to the medial and superior aspects of the joint $[75,77]$. This technique can be employed in ankles that do not have much structural deformity. Once the articular surfaces are properly prepared, the talus is compressed into the medial axilla and fixed by a variety of measures including crossed screws [76] (Figure 8), plate and screws [75, 77] or external fixation/Ilizarov $[79,80]$ (Figure 9). Less commonly, an intramedullary ankle arthrodesis nail can be used for fixation but this must also cross the subtalar joint [78, 83] (Figure 10).

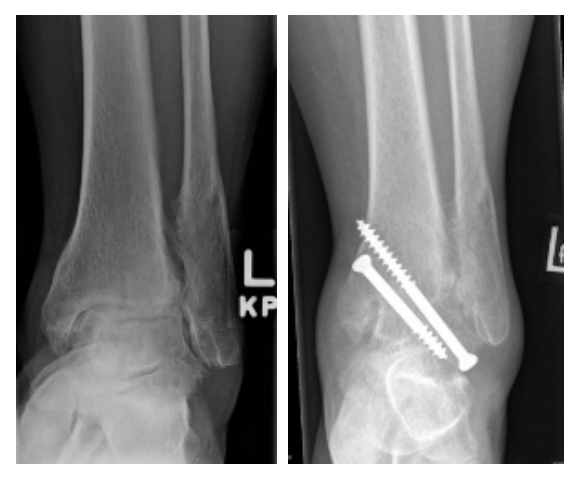

Figure 8. Left image showing severe OA changes but relatively normal structureal anatomy. Right image show fusion using crossed screws with the second screw entering the lateral process of the talus and crossing the joint pushing the talus into the medial axillay of the ankle mortice to achieve extra stability.
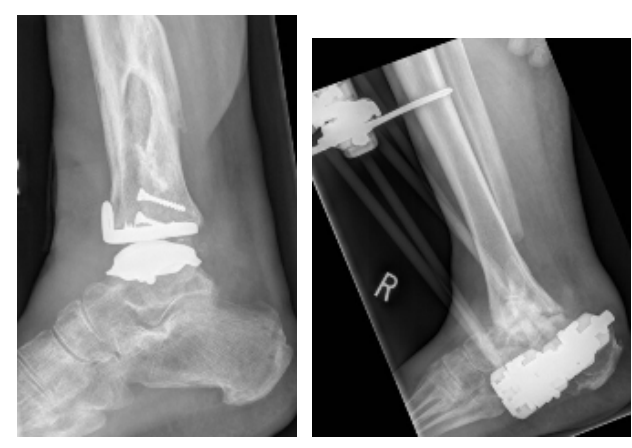

Figure 9. Total ankle replacement complicated by infection. Right image shows ankle replacement removed and attempt fusion using spanning external fixator. 

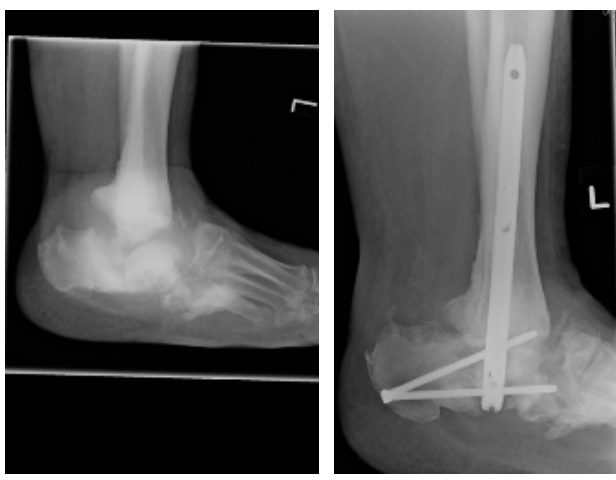

Figure 10. Severe Charcot arthropathy in an obese diabetic patient. Limb salvage ankle fusion using an ankle arthrodesis nail.

In ankles with more significant deformation, especially with bone loss, a more extensive approach may be considered. This entails a lateral approach and employs a fibular osteotomy approximately $5-6 \mathrm{~cm}$ above the syndesmosis [72, 82] (Figure 11). The fibula is osteotomized obliquely over a $1 \mathrm{~cm}$ distance and displaced from the tibia using anterior dissection while leaving an intact posterior hinge. The distal fibular segment is split sagitally and the inner $1 / 2$ removed so that the other $1 / 2$ (still attached by the posterior soft tissue hinge) can be used as a lateral buttress plate across the joint. Through this lateral incision, the surfaces of the talus and tibial plafond can be prepared for the fusion. This can be supplemented by a small anterior medial incision over the medial gutter for that surface preparation. This approach allows contouring of the fusion surfaces to achieve good bone apposition and to correct mal-alignment. Often supplemental bone graft is required to fill eroded defects. Fixation can be carried out by screws including two screws from the fibular strut into either the tibia and the talus or the tibia alone (to allow talar compression during weightbearing postoperatively).

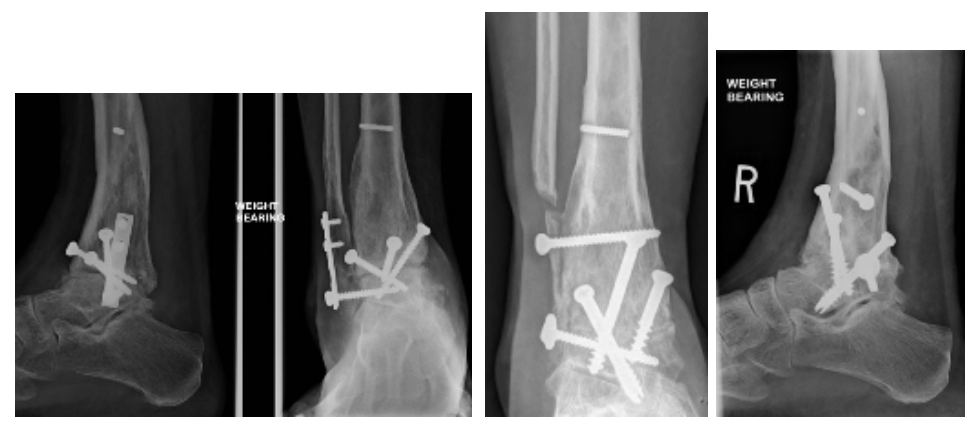

Figure 11. First 2 images on the left show attempted fusion using inadequate screw fixation with screws barely crossing the fusion site while the fibula was left intact despite screws inserted across it. Revision fusion demonstrating the use of the distal fibula as a strut plate graft with proper screw placement to achieve fusion. 
Some surgeons prefer the posterior approach to the ankle for fusion [84-86]. This approach can be through or beside the Achilles tendon and can provide good exposure while minimizing risk to compromised anterior soft tissues when present. This approach can be extended to incorporate the subtalar joint in the fusion mass and a blade plate is often used for fixation.

In the circumstances of infection or soft tissue compromise, alternative approaches should be considered. The ankle joint can be adequately debrided with minimal invasiveness using arthroscopy $[79,87,88]$ potentially decreasing soft tissue complications. Alternative fixation such as external fixators [78] or the Ilzarov [83] can be used to limit the issues of hardware insertion during ongoing infection. These devices may also be able to correct deformity over time.

As noted, ankle fusion can provide excellent relief of pain with significant improvement of function [89]. Surgical techniques have advanced such that it should be expected to have a $90-100 \%$ fusion rate in uncomplicated cases. Meticulous soft tissue handling and intraoperative care can mitigate complications. Despite these results, ongoing concerns of limitations of ankle motion and the increased stress on surrounding joints resulting in increased incidence of arthritis has led to the development of the total ankle arthroplasty as will be discussed in the next section.

\section{Arthroplasty implants}

\subsection{Historical perspective}

Total ankle arthroplasties were first introduced in the 1970s [90]. The first prosthesis, created by Lord and Marotte, was designed as an inverted total hip replacement [91]. Although Lord and Marotte's primary results were failures, over the next 20 years, more than 23 designs were developed using that generation's technology from hip and knee replacements characterized by cemented, two component, constrained implants [92]. Despite good initial results using this technology, there were problems with component loosening, severe osteolysis, infection, impingement and soft tissue breakdown [93, 94]. Kitaoka reviewed results of the first generation TAR that included three studies with greater than 5 year follow-up and found a $41 \%$ revision rate [95]. The high rate of failure for these first generation implants and difficult salvage procedures tempered enthusiasm and led to questions as to whether the ankle joint could be replaced successfully [92, 95-97]. Hintermann accurately stated, "in an era of joint replacement surgery, ankle procedures have failed to achieve what has been accomplished with other joints" [98].

The first generation implants were designed without proper understanding of ankle biomechanics [99, 100]. The ankle was assumed to be a hinge joint and the rotational and translational motions were not recreated which lead to loosening [97, 101]. These implants were either highly constrained or unconstrained. The highly constrained implants led to large shear and rotational forces that were distributed through a small joint surface and even smaller prosthesis interface $[94,102,103]$. The unconstrained implants were 
unstable due to lack of attention to soft tissue balancing and failure to address soft tissue impingement [94, 104, 105].

In general, ankle arthroplasties were implanted through an anterior approach to the ankle but the importance of the soft tissue envelope was underestimated and excess traction on the skin led to wound complications [92,93]. The guides, jigs and instruments were not well designed and sizing was inaccurate so implants were mal-positioned and malleolar fractures were common [92]. Patients were left with mal-aligned implants either because the angular deformity was not corrected at the time of surgery [5] or because the ligaments were ignored leading to problems with functional mal-alignment despite good intraoperative positioning [94, 102]. Finally, most implants were cemented and required large bone resection including up to $17 \mathrm{~mm}$ on the tibial side and $7 \mathrm{~mm}$ on the talar side. This caused the implant to be cemented into soft cancellous bone which was unable to support the bone cement interface $[92,106]$. Subsidence was further exacerbated by non-anatomically shaped, undersized implants [5, 92, 93, 107]. The aggressive bone resection of the tibia also changed the level of the ankle axis causing alterations in the ankle biomechanics [5]. When function was assessed via gait analysis, there was not as much improvement as had been anticipated. Gait analyses of the first generation implants revealed that patients were subconsciously protecting the joint by not bearing weight normally across the ankle despite denying pain and were not using normal ankle dorsiflexion in the stance phase despite adequate passive dorsiflexion on physical exam $[4,5,106]$.

\subsection{Biomechanical considerations}

In order to understand the reasons for failure and to design a better total ankle arthroplasty, it was important to understand the biomechanics of the foot and ankle. The ankle is a highly constrained joint that does not function as a simple hinge joint because the axis is oblique extending further plantar and posterior on the lateral side. This creates eversion with dorsiflexion and inversion with plantarflexion [108]. Further, the axis of rotation changes throughout the range of motion so that when the ankle moves from a plantarflexed to a dorsiflexed position there is a combination of distraction, sliding and compression [108, 109]. Finally, there are rotational and translational movements that also need to be recreated with a replacement arthroplasty [94, 110].

The most important concepts in the design of an ankle arthroplasty are constraint and congruency. Constraint can be defined as the resistance of an implant to a particular degree of freedom of motion such as anterior-posterior translation or axial rotation [94]. In highly constrained implants such as a hinged ankle replacement, all axial torque forces are translated through the bone-prosthesis interface as shear forces that can lead to component loosening $[92,111]$. Congruency or conformity can be defined as the closeness of fit of the various components of the implant $[92,94]$. In a fully conforming implant, the articular surface of the tibia has the same radius of curvature as the articulating surface of the talus in both anteriorposterior and medial-lateral directions. This decreases the wear rate because the polyethylene contact stress remains below the fatigue threshold for delamination and pitting [92]. In a partially conforming or incongruent implant the round talus articulates with a flat tibia or 
there are differences in the radius of curvature of the 2 surfaces [92]. The optimal design for a total ankle replacement is with bearing surfaces that are not only highly conforming to ensure contact throughout the bearing surface thus reducing wear but also sufficiently constrained to give the implant sufficient inherent stability to minimize shear stresses at the prosthesis-bone interface [94, 112].

Second generation implants used these two concepts to improve the design of total ankle arthroplasties. In general, the two primary alternatives were 1) a two component, partially conforming ankle replacement which replaced all three articulations by changing the ankle into a two bone joint by fusing the distal tibia-fibular joint $[5,92]$ or 2) a three component design which resurfaced the tibio-talar joint and the talar side of the lateral and medial gutters [5, 92]. Third generation implants are more anatomically designed and rely on ligament support as well as hindfoot "balancing" to allow the components to recreate the ankle biomechanics [113].

Gait studies of the newer implants show a satisfactory recovery of the natural overall mobility of the ankle joint in all three planes of motion [114]. Further, in three component designs, there may be some movement of the polyethylene separate from the other components which helps to restore normal biomechanics [114]. Functional motion and muscle-generated moments during walking improved at the ankle joint after arthroplasty - especially plantar flexor muscle function. This function is important because it restrains the forward movement of the tibia during the first half of the gait cycle and brings about plantarflexion of the ankle during the propulsive phase of gait [99]. Brodsky has shown significant improvement in velocity, step length for operated side, total ankle ROM during gait, and maximum sagittal ankle joint power at push-off [115].

\subsection{Current implants}

Lewis has described key aspects for a successful ankle joint arthroplasty based on careful review of the first and second generation implants [97]. It is important that implant size be designed to balance the need for minimal bone resection with the requirement for sufficient implant to distribute stresses over a large area to decrease the risk of subsidence [97]. The anatomical axis needs to be recreated while also understanding that there is large variability in the axis between individuals [97, 116]. It is also important to recreate all the motions at the ankle joint instead of just plantar flexion and dorsiflexion [97]. This includes talar tilt as the ankle is coupled to the subtalar joint to accommodate to uneven ground, and the rotational motion of internal rotation coupled to plantar flexion and external rotation coupled to dorsiflexion. Failure to understand and recreate these motions will place abnormal stress through the implant-bone interface [97]. It is critical to understand the necessity of ligament support for ankle stability [5]. An implant designed to be sufficiently stable to negate the need for ligament support will transfer abnormal stress to the bone-implant interface leading to loosening [94, 102, 103]. In contrast, an implant designed with low stability that is implanted into an ankle without sufficient ligamentous support will fail due to component mal-alignment or dislocation of the polyethylene [94, 97, 104, 105]. The requirement to withstand high loads means that ultra-high molecular weight polyethylene is generally recommended [97, 117]. 
Third generation ankle arthroplasties are now in use. The new designs show better understanding of ankle biomechanics and allow for sliding and rotational movements [92]. There are many different third generation implants used across the world and the following discussion provides a representative sample of those commonly used in the Western world but is not inclusive of all implants. The implants will be discussed in relation to design rationale.

The common surgical approach, as will be discussed in further detail later, is an anterior approach in the interval between tibialis anterior tendon and extensor hallucis longus tendon. The neurovascular bundle is carefully protected under the extensor hallucis longus tendon. The major disadvantage of this approach is the high rate of wound healing complications [92, 118, 119]. The BOX ankle replacement (Finsbury Orthopaedics, Leatherhead, Surrey, UK) uses an anterolateral approach between the extensor digitorum longus tendon and the peroneal tertius tendon [112]. The Eclipse (Integra LifeSciences, Plaisboro, NJ) is inserted through either a medial (preferred) or lateral approach [112]. The disadvantage of this approach is the need for fixation of the disrupted medial or lateral malleolus.

The current implants are either mobile ( 3 component design) or fixed ( 2 component design) bearing [101]. Mobile bearing designs allow for greater congruence, which can increase the risk of dislocation, but they share the stress through 2 articular surfaces, which may increase weardue to "back side wear" [101, 120]. There is also the potential for "overstuffing" the joint with three component designs in an attempt to reduce the chance of polyethylene dislocation [121]). Overstuffing tightens the joint, increases ligament strain, decreases range of motion and increases the shear stress at the bone-prothesis interface [5, 121]. Fixed bearing designs increase the constraint so they may have higher rates of loosening but have decreased back side wear if the locking mechanism is intact [94, 101]. Current mobile bearing designs include the STAR (Waldemar Link, Hamburg, Germany; 1978)(Figure 12), BuechelPappas (Endotec, South Orange, NJ; 1989), Salto (Tornier, Saint Ismier, France; 1997), Hintegra (Integra LifeSciences/Newdeal, Lyon, France; 2002)(Figure 12), Mobility (DePuy International, Leeds, UK; 2005)(Figure 12), BOX (Finsbury Orthopaedics, Leatherhead, Surrey, UK; 2005), CCI Evolution (Van Straten Medical, The Netherlands, 2007), and Zenith (Corin, Cirencester, UK; 2009). Two component designs include the Agility (DePuy/Ace, Warsaw, IN; 1985)(Figure 13), TNK (Kyocera, Kyoto, Japan; 1996), INBONE (Wright Medical Technologies, Arlington, TN; 2005)(Figure 13), Salto Talaris (Tornier, Saint Ismier, France; 2006), and Eclipse (Integra LifeSciences, Plainsboro, NJ; 2007).

Most ankle arthroplasty implants are constructed from cobalt-chromium alloys which are hard, corrosion resistant and biocompatible (Hintegra, Agility, Mobility, Inbone talus, BOX, Salto and Salto-Talaris, and Buechel-Pappas). The CCI Evolution adds molybdenum to the alloy to increase strength (Van Straten Medical, The Netherlands, 2007). The STAR and Inbone (tibia only) use titanium implants which are softer but can be more porous to allow for better ingrowth. The TNK is a ceramic implant (Kyocera, Kyoto, Japan; 1996).

Initial implants were cemented; however, due to the high rate of failure, most implants today are uncemented relying on bone ingrowth stimulated by hydroxyapatite coating, sintered metal beads, plasma spray metals or fiber metals [101]. The different methods to encourage bony ingrowth include ensuring the metal is porous such as the Hintegra which 
is $20 \%$ porous [92]. Some implants, like the STAR, use a single or dual plasma spray. Others use a thin film ceramic coating. The Buechel-Pappas and CCI Evolution use a porous coating covered by a titanium nitride thin-film ceramic [92] which also improves the smoothness of the surface. The Zenith uses the trademarked "BONIT" coating which is the application of a thin calcium phosphate layer to the titanium plasma spray. The last common technique is the use of hydroxyapatite incorporated in the Hintegra [92].

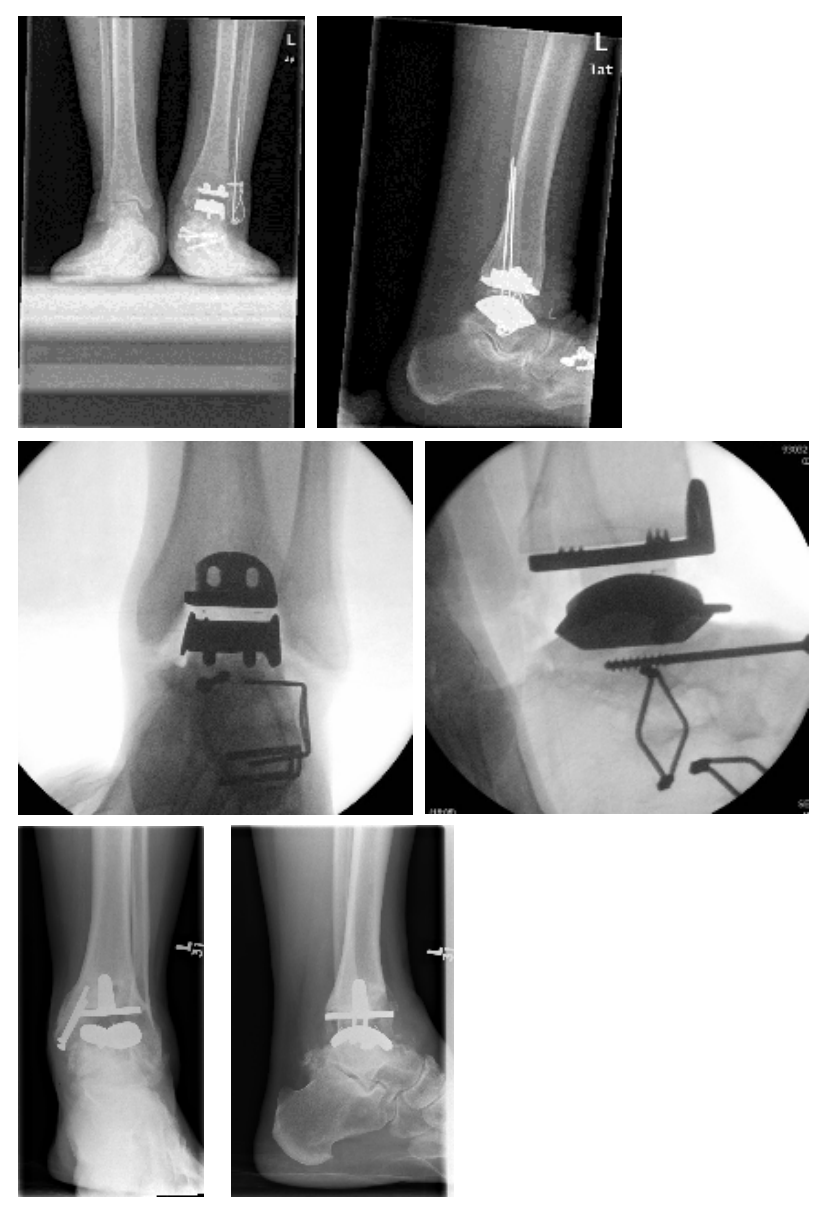

Figure 12. Radiographic images of three currently used mobile bearing total ankle arthroplasty designs. The top two images are STAR, middle two images are Hintegra and the bottom two images are Mobility. 

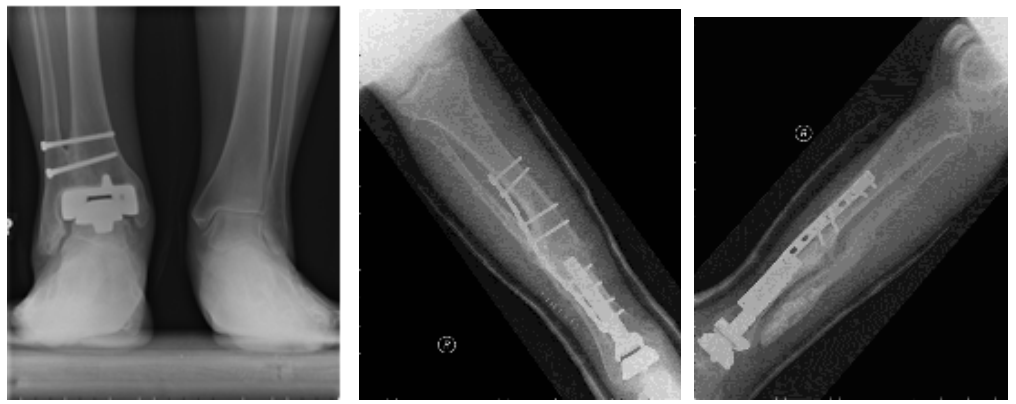

Figure 13. Radiographic images of two currently used fixed bearing total ankle arthroplasty designs. The left image is Agility while the right two images are Inbone.

In most implants the tibial cut is made first. Unlike the knee, the ankle cannot be dislocated sufficiently to allow for intramedullary guides to make the tibial cuts so all ankle arthroplasties, with the exception of the Inbone, use extramedully tibial guides with or without a foot holder. The Inbone uses an external guide and radiographs to guide the insertion of an intramedullary reamer and combines it with a foot holder to place the tibial cutting guide [112]. After the tibial cut has been completed and the intramedullary canal has been reamed, the tibial stem and plate components are inserted one at a time into the joint and built inside the ankle and tibia. The downside of using this intramedullary technique is that the subtalar joint is violated as the tibial canal is reamed retrograde through the calcaneus, talus and then tibia.

Other implants, such as the Buechel-Pappas, Mobility and Agility use intramedullary posts on the tibia to provide fixation by creating an anterior cortical window to insert the tibial component which is then replaced and generally heals without incident. If the tibial component does not have an intramedullary stem, the fixation can be with a fin (CCI Evolution), a fin with a cylinder (Salto), double cylinders (STAR), bars (BOX) or an anterior shield which may or may not be augmented with screws (Hintegra).

Tibial components can either rely on support from the intramedullary stem (Inbone) or cortical bone anteriorly and posteriorly (Hintegra). Some tibial components are rectangular and others are trapezoidal designed to be larger anterior than posterior (STARand CCI Evolution). Finally, while most are flat, they can be designed with a curve (BOX).

The design of the talus implant can be with a symmetrical curve (STAR, Buechel-Pappas, INBONE, Mobility) or asymmetrical so that the radius of curvature for the medial side is less than that for the lateral side (Salto, Hintegra, BOX, CCI Evolution). Most implants resurface the talus (STAR, Buechel-Pappas, Salto, Hintegra, Mobility, BOX, CCI Evolution, and Zenith), but the Inbone and Agility use a flat talar cut. Some designs replace the medial and lateral talar articulations (STAR, Buechel-Pappas, TNK, Salto, and Hintegra) while others do not (Agility, BOX, Mobility, CCI Evolution, and Zenith,). Finally, the polyethylene is ultra-high molecular weight polyethylene in the STAR, Buechel-Pappas, Salto, Hintegra and Inbone. 
In summary, the third generation implants have been designed using the knowledge gained from more indepth study of the anatomy and biomechanics of the ankle joint as well as the causes of the failures of the first and second generation implants. When choosing an implant, the surgeon should consider the approach, the need for intramedullary guides and fixation of the tibial component, the relative importance of preserving talar bone stock by resurfacing the talus as opposed to a flat cut, the need for replacing the medial and lateral articulations of the talus, and the role for ultra-high molecular weight polyethylene.

\section{Surgical considerations}

Clinical indications for total ankle arthroplasty include end stage ankle arthritis that has exhausted all non-operative and joint-sparing operative treatments in a patient willing to undertake the risks of a major surgical procedure. Contraindications to this procedure include:

- Active infection

- Compromised soft tissues

- Inadequate blood supply

- Peripheral neuropathy (including Charcot arthropathy)

- Significant lower extremity neuromuscular impairment

- Severe ligamentous laxity

- Excessive malalignment

- Avascular necrosis of a significant portion of the tibia or talus

- Severe osteoporosis

- Inadequate bone stock

- Skeletal immaturity

- High demand lifestyle

- Pertinent metal allergy

- Sensory or motor dysfunction

Age is not explicitly mentioned as a contraindication in the literature. The safe zone appears to be somewhere after skeletal maturity and in conjunction with the assumption of a low demand lifestyle. Excessive malalignment is a nebulous term. The commonly accepted range is from 15-20 degrees of varus or valgus to not surgically correctable. It would appear that excessive malalignment is relative to the surgeon's skill and experience. Obesity as a contraindication to total ankle arthroplasty is controversial and was not correlated to aseptic loosening in a recent article [122]. 


\subsection{Surgical approach}

There are several different types of ankle arthroplasty systems currently on the market as discussed. Each system has unique features best explained by the surgical technique manual provided by the company marketing that system. There are, however, certain common aspects and principles of all of the systems which we will outline in this section.

\subsection{Preoperative planning}

The condition of the soft tissue envelope including locations of scars and documentation of neurovascular status are important when planning a total ankle arthroplsty. Ankle arthroplasty may be contraindicated in some cases due to an impaired soft tissue envelope or inadequate blood supply to the foot.

Long leg weight-bearing views will help identify concurrent ipsilateral limb deformities which may affect ankle alignment. Anteroposterior and lateral views of the tibia are also important because intraoperative alignment is usually referenced off of the tibia. Weightbearing anteroposterior and lateral views of the ankle and foot are important to assess the joint being replaced but also to identify coexisting deformities and/or arthritis affecting the rest of the foot which may affect the surgical plan resulting in additional procedures that can be performed in a staged manner or concurrently depending on surgeon skill and preference.

\subsection{Positioning}

The patient is positioned supine on a radiolucent table to allow fluoroscopic guidance of the procedure. The ipsilateral hip is supported to prop the foot perpendicular to the floor to allow easy access to both the medial and lateral aspects of the joint and enable evaluation of alignment intraoperatively. Rotation of the foot relative to the leg on the contralateral side should be noted before prepping and draping to determine what is normal for that patient.

\subsection{Prepping and draping}

A thigh tourniquet is utilized to provide hemostasis during the procedure. The leg is prepped and draped as a free extremity right up to the tourniquet to provide access to the knee. Many total ankle arthroplasty systems use the length of the tibia and an external alignment device as a guide to proper alignment.

\subsection{Surgical exposure}

The most common surgical approach to the ankle for insertion of a total ankle arthroplasty is the anterior approach. Some systems that involve tibiofibular fusion as part of the procedure may require and an additional lateral incision but still utilize the anterior approach as well. An incision is made over the anterior aspect of the ankle midway between the malleoli (Figure 14). The incision needs to be long enough to allow placement of the distal tibial cutting block and visualization of the talar neck. Care is taken to minimize injury to the branches of the superficial and deep peroneal nerves. The retinaculum is then split to expose the 
underlying tendons. The extensor hallucis longus tendon will be retracted laterally to protect the underlying neurovascular structures which should be located deep and lateral to the extensor hallucis longus tendon (Figures 14 and 15). If possible, the sheath of the tibialis anterior should be left intact to prevent undue pressure on the wound post-operatively (Figure 16). The anterior capsule is incised vertically and then peeled away in a subperiosteal plane medially and laterally to expose the joint (Figure 17). One should be able to see the medial malleolus clearly but the lateral malleolus is more posterior and often is not as easily seen.

Distal tibial osteophytes are now removed taking note of a commonly occurring large osteophyte anterior to the fibula. Care should be taken to differentiate the osteophyte from the fibula itself. There will also be osteophytes on the neck of the talus which can be removed with a curette, rongeur or burr to reestablish its normal contour. This will help with cutting block placement and ankle positioning when cuts are made (Figure 18).

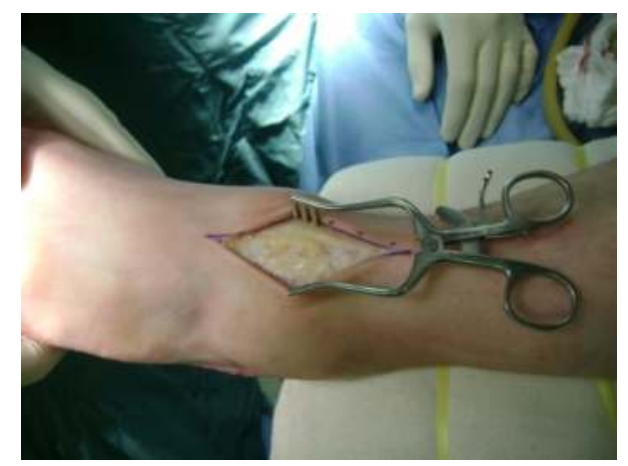

Figure 14. Anterior incision midway between the malleoli. Toes are to the left and knee is to the right. Blunt retractors and extreme soft tissue care are required.

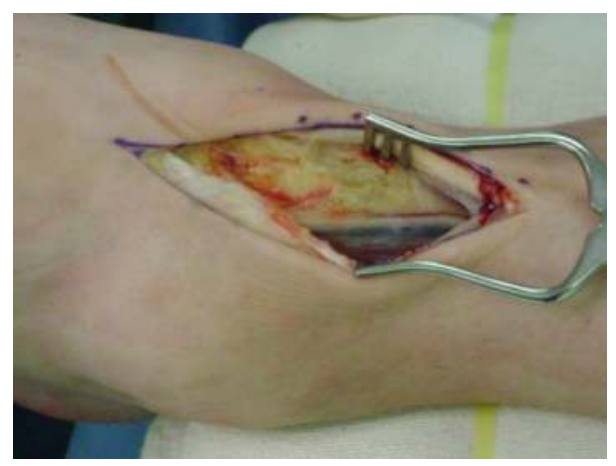

Figure 15. Exposure of the neurovascular bundle by retraction of the extensor hallucis longus tendon. 


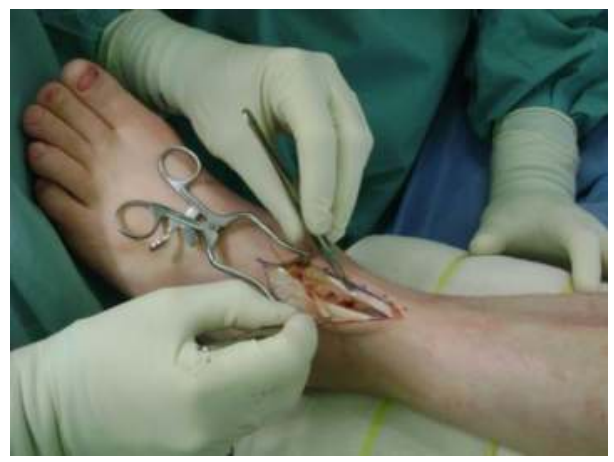

Figure 16. Tibialis anterior sheath.

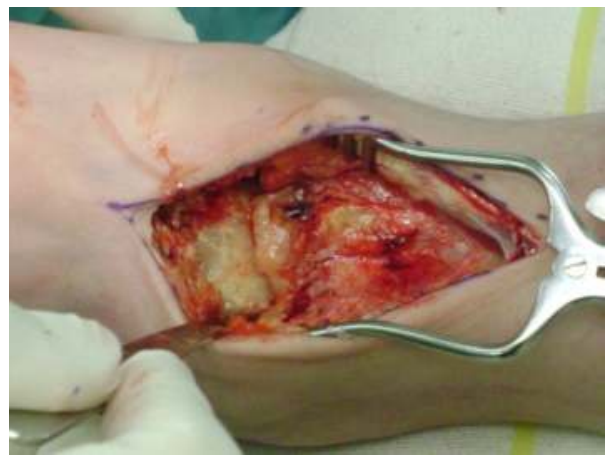

Figure 17. Exposure of the joint.

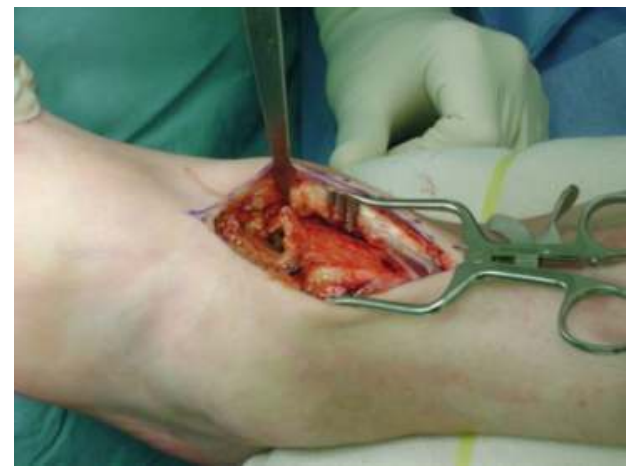

Figure 18. Anterior tibial osteophyte requires removal. 
The soft tissues should be handled with extreme caution. Blunt self-retaining retractors should be repositioned periodically to prevent prolonged pressure on the soft tisse. Care should be taken with the bone as well. Levering on the medial malleolus may result in fracture. Notching the fibula during the distal tibial resection can result in fracture as well. Exposure can be facilitated by instruments such as laminar spreaders, distractors and various retractors. Performing the talar cuts can also facilitate removal of posterior malleolar fragments in systems that require this.

\subsection{Alignment}

The tibia is used to guide placement of the cutting blocks either with an external rod placed parallel to the shaft of the tibia by direct visualization or overlapped with the tibial canal fluoroscopically. The distal tibia is cut perpendicular to the anatomical axis of the tibia in the coronal plane. Most systems build in a posterior slope to the distal tibial cut in the sagittal plane and this can be adjusted in certain cases to allow more or less slope depending on the patient's needs. Longitudinal alignment of the talar component is usually in line with the second ray of the foot.

\subsection{Ligamentous balancing}

Ligamentous balancing is not yet as sophisticated as for total knee arthroplasty. The posterior capsule is resected during the removal of the posterior malleolus. Medially, the deltoid ligament can be released in a subperiosteal plane from the medial malleolus and/or talus, pie-crusted, released mid-substance or relatively lengthened through a medial malleolar osteotomy [123-126]. Laterally, the talofibular ligaments should be treated with care. Aggressive release from the talus can result in iatrogenic lateral instability. If there is a preexisting lateral instability, consent should be obtained for a lateral ligament reconstruction if required. Generally, stability is assessed after the bony cuts are made. A gastrocsoleus slide or Achilles tendon lengthening may be required if the ankle does dorsiflex past neutral after the ankle arthroplasty has been performed.

\subsection{Closure}

Repair of the extensor retinaculum during closure is very important. If left uncovered, the tibialis anterior may erode through the incision putting the arthroplasty and possibly even the leg at risk.

\subsection{Post-op care}

In the case of an uncomplicated ankle arthroplasty with no extra ligament reconstruction or fusion the patient has a short period of non-weight-bearing activity in a splint or cast followed by weight-bearing activity in a cast until the six week post-operative visit. Subsequently, physiotherapy to work on dorsiflexion and plantar flexion, gait retraining and leg strengthening is initiated. 
There are no guidelines in regards to deep venous thrombosis (DVT) prophylaxis after total ankle arthroplasty but it would prudent to use propylaxis in patients with significant risk factors. Obesity, previous venous thromboembolism, and absence of full postoperative weightbearing were identified as risk factors for the development of DVT in a study on total ankle arthroplasty in the obese [122]. The importance of these risk factors was echoed by Barg et al in their article looking at risk factors for DVT in total ankle arthroplasty patients who were give thromboprophylaxis [127]. Other factors associated with increased incidence of DVTs include cancer, use of high dose estrogen replacement, and smoking.

\subsection{Radiological follow-up}

Ankle replacements should be followed radiologically as well as clinically in the post-operative period including weightbearing anteroposterior and lateral x-rays. One should look for changes in position which would indicate loosening of the components. Persistent periprosthetic lucencies should be followed for progression. There are a variety of angular measurements based on anatomical axes and component position as well as standardized distances from anatomical landmarks to component landmarks that can be used to assess technical success of prostheses implantation or subsequent subsidence [128].

\subsection{Complications}

The complications associated with total ankle arthroplasty would be familiar to any shoulder, hip or knee arthroplasty surgeon. and can be classified in different ways. Glazebrook et al recently published an evidence-based classification system that groups complications according to their correlation with failure of the prosthesis [3]. The goal of this classification system is to provide prognostic information to help surgeons deal with complications more effectively. To develop this classification system, the current literature on second and third generation prosthetic ankle arthroplasty outcomes were reviewed. Based on this information they were able to provide a summary of total ankle arthroplasty implant survival and complication rates. Twenty studies met their inclusion criteria with follow-up periods ranging from two to twelve years. In total 2,386 ankle arthroplasties were reviewed. They reported nine main complications including:

- Subsidence $-10.7 \%$

- Aseptic loosening $-8.7 \%$

- Intra-op fracture $-8.1 \%$

- Wound healing problem - 6.6\%

- Technical error $-6.0 \%$

- Implant failure $-5.0 \%$

- Non-union $-4.4 \%$

- Post-op bone fracture $-2.0 \%$ 
- Deep infection $-1.7 \%$

These complications were compiled into three groups depending on how likely the complication would lead to failure of the arthroplasty. The three complications that lead to arthroplasty failure greater than $50 \%$ of the time were deep infection, aseptic loosening and implant failure. Other complications not included in this review that should be noted include tendon laceration, nerve injury, and instability (due to ligamentous imbalance). Impingement is another complication that is minor in terms of prosthesis survival but can have a significant effect in terms of patient satisfaction. It is usually medial and can be caused by osteophytes, scar tissue or tibialis posterior tendon degeneration.

\subsection{Outcomes}

In order to evaluate the outcomes of contemproary total ankle arthroplasty, it is instructive to look at the results published by joint registries from around the world. While not as common as registries for total hip and knee arthroplasty, there are at least four registries reported in the literature.

In 2007 the Norwegian registry reported on their experiences with total ankle arthroplasty [129]. This registry looked at 257 joints implanted between 1994 and 2005. This included a small number of cemented implants. The average age at the time of implantation was 58 for women and 60 for men. The The 5-year survival rate was $89 \%$ and the 10 year survival rate was $76 \%$. There was no difference in the survival rates of the cemented and cementless prostheses.

The New Zealand registry reported on 202 joints in total also in 2007 [130]. This included both second and third generation prostheses. The average age of the patients at the time of implantation was 65 . The most common diagnosis was primary osteoarthritis. The 5-year survival rate was $86 \%$.

In 2010 the Finnish registry published their results on 573 total ankle arthroplasties [131]. These were all third-generation mobile-bearing designs. The average age of the patients was 55. The 5-year survival was $83 \%$.

The Swedish Registry reported on the ten year survival of 780 third-generation total ankle arthoplasties in 2011 [132]. The registry included a variety of uncemented, three component implants. Revision rate was used as the primary outcome variable. The overall 10 year survival rate was $69 \%$ although this increased to $78 \%$ of the STAR prostheses were excluded. It is interesting to note that the other registries did include the STAR prostheses in their results.

Overall, age, sex, and diangosis did not affect survival in the Norwegian, New Zealand or Finnish registries. The Swedish registry, however, found that the risk for revision was higher in female patients under 60 years of age with a diagnosis of primary osteoarthritis or posttraumatic arthritis.

There have been a lot of outcome studies published in recent years but a disproportionate number have been published by the prostheses designers themselves according to La- 
bek et al [133]. Approximately 50\% of the publications reporting on total ankle arthroplasty outcomes have been produced by implant developers. Furthermore, the revision rates from the national registries (Swedish, Norwegian and New Zealand) have a much higher revision rate than those published in peer-reviewed scientific journals that include the manufacturers' reports [133].

That said, it is still worthwhile to look at all of the published data. There have been three relatively recent reviews of total ankle arthroplasty outcome study data [69, 134, 135]. The most recent one was published by Gougoulias et al in 2010 [134]. They included thirteen Level IV studies looking at 1105 total ankle arthroplasties. The most common diagnosis was posttraumatic arthritis. The overall failure rate was approximately $10 \%$ at 5 years. Range of motion did not change in one study and improved by $4-14$ degrees in four others. In the studies reporting them, there were superficial wound complications in $0-14 \%$, and deep infections in $0-4.6 \%$. In seven studies, rates of residual pain in the hindfoot ranged from 23 to $60 \%$. Interestingly, the most common sporting activities after total ankle arthroplasty were identified as swimming, cycling and fitness/weight training.

In an older review published in 2007 by Haddad et al, the intermediate outcomes of total ankle arthroplasty and ankle fusion were compared [69]. They looked at ten papers which evaluated total ankle arthroplasty and thirty-nine which looked at ankle fusion. The mean American Orthopaedic Foot and Ankle Society Ankle Hindfoot score was 78.2 for the arthroplasty group and 75.6 for the fusion group. The average age of patients undergoing arthroplasty was 58 and fusion 50. The majority of the fusion patients were male, while the major of the arthroplasty patients were female. Rheumatoid arthritis was the primary indication for total ankle arthroplasty, posttraumatic arthritis for fusion. The 5-year implant survival rate for the arthroplasty group was $90 \%$, while the 10 -year survival rate was $77 \%$. They noted that a weakness of their review was that there were no direct comparisons of total ankle arthroplasty to ankle fusion.

Stengel et al's review in 2005 identified 10 adequate studies with a total of 497 ankle arthroplasties [135]. The total ankle arthroplasty patients showed a mean improvement in hindfoot scores of 45.2 points. Range of motion improved an average of $6.3 \%$. Complications ranged from a $1.6 \%$ deep infection rate to a $14.7 \%$ impingement rate. The five year prosthesis survival rate was $90.6 \%$.

Since the publication of the most recent of the above reviews, there have been some other publications of note. The long-term results of the United States STAR trial were published in 2011 [136]. They prospectively followed 80 patients treated with 84 STAR prostheses. The average age at implantation was 61 years. Their American Orthopaedic Foot and Ankle Society ankle-hindoot scores improved from an average of 42.7 to 81.9 points. Average range of motion was 39.5 degrees. Implant survival was $96 \%$ at 5 years and $90 \%$ at 10 years.

Bonnin et al recently published the long term follow-up of patients they had implanted with the SALTO total ankle arthroplasty and reported on previously [137]. They analyzed 98 prostheses with and average followup of 8.9 years. The mean American Foot and Ankle Society ankle-hindfoot score was 79. Range of motion was 27 degrees. The survival rate was 
$85 \%$ with an end point being the revision of a component. Limitations of this study included the series of patients being operated on by the implant designers and the implants and technique changed during the course of the study.

Wood et al compared the STAR implant to the Buechel-Pappas implant in a randomised trial [138]. The study involved 200 joint replacements. They were followed out for 6 years. The STAR survivorship was $95 \%$ and the Buechel-Pappas $79 \%$ with the end point being revision. The difference was not found to be statistically different.

Total ankle arthroplasty has been shown to improve ankle joint mechanics. Hahn et al demonstrated that both arthroplasty and fusion impoved gait function and reduced pain but that arthroplasty patients gained a more natural ankle joint function with increased range of motion [139]. Piriou et al were also interested in how gait was affected by total ankle arthroplasty [140]. They compared 12 arthroplasty patients to 12 fusion and 12 control patients. Neither the arthroplasty patients nor the fusion patients regained normal movement or walking speed, but the arthroplasty group had greater movement at the ankle, more symmetrical timing of gait and better restored ground reaction force patterns than the fusion group. The fusion group had a faster gait and longer step length than the arthroplasty group. Schuh et al compared 21 ankle fusion patients to 20 total ankle arthroplasty patients in regards to sport and recreational activities as well as functional outcome directly [89]. They found no signifcant difference between the groups concerning activity levels, participation in sports activities.

Finally, despite improved motion and decreased pain, total ankle arthroplasty does not result in weight loss. Penner at al investigated weight loss after total ankle arthroplasty and found that although pain and disability were reduced in overweight and obese patients after both ankle arthroplasty and fusion, the mean body mass index (BMI) remained unchanged [141].

\section{Conclusion}

Ankle arthritis can be a debilitating disorder as disabling mentally and physically as hip arthritis. There are a myriad of nonoperative and joint sparing operative treatments that can improved symptoms but do not arrest the disease process. When end-stage osteoarthritis develops, the gold standard has been ankle fusion. Some limitations to a successful ankle fusion such as stiffness and arthritic progression of surrounding joints as well as the successful replacements of the hip and knee joint led to the development of total ankle arthroplasty. Second and third generation prostheses have markedly improved function and long-term results compared to first generation prostheses. Although the procedure can be technically demanding and is associated with numerous potential complications, patients generally experience improved function and decreased pain. Based on current literature, it seems reasonable to expect an $80 \%$ prosthesis survival after 10 years. Further investigations into ankle joint mechanics, risk factors for implant failure and methods to minimize complications should lead to additional improvements in long-term outcomes. Finally, prospective, long- 
term direct comparison studies of ankle fusion versus total ankle arthroplasty are required to determine which procedure is best for which patient.

\section{Acknowledgements}

Orthotic photographs provided by Orthotic Solutions, Edmonton, Alberta, Canada.

\section{Author details}

Nadr M. Jomha, Angela Scharfenberger, Gordon Goplen and M. Elizabeth Pedersen

*Address all correspondence to: njomha@ualberta.ca

Division of Orthopaedic Surgery, Department of Surgery, University of Alberta, Edmonton, Alberta, Canada

\section{References}

[1] Buckwalter JA, Saltzman C, Brown T. The impact of osteoarthritis: implications for research. Clin Orthop Relat Res. 2004 Oct(427 Suppl):S6-15.

[2] Saltzman CL. Ankle Arthritis. In: Coughlin M, Mann R, Saltzman C, eds. Surgery of the foot and ankle. 8th ed. Philadelphia, PA: Mosby Elselvier 2007:928.

[3] Glazebrook M, Daniels T, Younger A, Foote CJ, Penner M, Wing K, et al. Comparison of health-related quality of life between patients with end-stage ankle and hip arthrosis. J Bone Joint Surg Am. 2008 Mar;90(3):499-505.

[4] Stauffer RN, Chao EY, Brewster RC. Force and motion analysis of the normal, diseased, and prosthetic ankle joint. Clin Orthop Relat Res. 1977(127):189-96.

[5] Thomas RH, Daniels TR. Ankle arthritis. J Bone Joint Surg Am. 2003 May;85-A(5): 923-36.

[6] Valderrabano V, Horisberger M, Russell I, Dougall H, Hintermann B. Etiology of ankle osteoarthritis. Clin Orthop Relat Res. 2009 Jul;467(7):1800-6.

[7] Khazzam M, Long JT, Marks RM, Harris GF. Preoperative gait characterization of patients with ankle arthrosis. Gait \& posture. 2006 Aug;24(1):85-93.

[8] Valderrabano V, Hintermann B, Dick W. Scandinavian total ankle replacement: a 3.7year average followup of 65 patients. Clin Orthop Relat Res. 2004 Jul(424):47-56.

[9] Bombardier C, Laine L, Reicin A, Shapiro D, Burgos-Vargas R, Davis B, et al. Comparison of upper gastrointestinal toxicity of rofecoxib and naproxen in patients with 
rheumatoid arthritis. VIGOR Study Group. The New England journal of medicine. 2000 Nov 23;343(21):1520-8, 2 p following 8.

[10] Silverstein FE, Faich G, Goldstein JL, Simon LS, Pincus T, Whelton A, et al. Gastrointestinal toxicity with celecoxib vs nonsteroidal anti-inflammatory drugs for osteoarthritis and rheumatoid arthritis: the CLASS study: A randomized controlled trial. Celecoxib Long-term Arthritis Safety Study. Jama. 2000 Sep 13;284(10):1247-55.

[11] Muller-Fassbender H, Bach GL, Haase W, Rovati LC, Setnikar I. Glucosamine sulfate compared to ibuprofen in osteoarthritis of the knee. Osteoarthritis Cartilage. 1994 Mar;2(1):61-9.

[12] Lopes Vaz A. Double-blind clinical evaluation of the relative efficacy of ibuprofen and glucosamine sulphate in the management of osteoarthrosis of the knee in outpatients. Current medical research and opinion. 1982;8(3):145-9.

[13] Reginster JY, Deroisy R, Rovati LC, Lee RL, Lejeune E, Bruyere O, et al. Long-term effects of glucosamine sulphate on osteoarthritis progression: a randomised, placebocontrolled clinical trial. Lancet. 2001 Jan 27;357(9252):251-6.

[14] Lee YH, Woo JH, Choi SJ, Ji JD, Song GG. Effect of glucosamine or chondroitin sulfate on the osteoarthritis progression: a meta-analysis. Rheumatology international. 2010 Jan;30(3):357-63.

[15] Hughes R, Carr A. A randomized, double-blind, placebo-controlled trial of glucosamine sulphate as an analgesic in osteoarthritis of the knee. Rheumatology (Oxford). 2002 Mar;41(3):279-84.

[16] Wandel S, Juni P, Tendal B, Nuesch E, Villiger PM, Welton NJ, et al. Effects of glucosamine, chondroitin, or placebo in patients with osteoarthritis of hip or knee: network meta-analysis. BMJ (Clinical research ed. 2010;341:c4675.

[17] Pekarek B, Osher L, Buck S, Bowen M. Intra-articular corticosteroid injections: a critical literature review with up-to-date findings. Foot (Edinburgh, Scotland). 2011 Jun; 21(2):66-70.

[18] Stitek T, Jong K, Gazzilo G, Lee C. Injection procedures: Osteoarthritis and related conditions. Newark, NJ: Springer Science and Business Media 2011:67-89.

[19] Abate M, Schiavone C, Salini V. Hyaluronic acid in ankle osteoarthritis: why evidence of efficacy is still lacking? Clin Exp Rheumatol. 2012 Mar-Apr;30(2):277-81.

[20] Migliore A, Giovannangeli F, Bizzi E, Massafra U, Alimonti A, Lagana B, et al. Viscosupplementation in the management of ankle osteoarthritis: a review. Arch Orthop Trauma Surg. 2011 Jan;131(1):139-47.

[21] DeGroot H, 3rd, Uzunishvili S, Weir R, Al-omari A, Gomes B. Intra-articular injection of hyaluronic acid is not superior to saline solution injection for ankle arthritis: a randomized, double-blind, placebo-controlled study. J Bone Joint Surg Am. 2012 Jan 4;94(1):2-8. 
[22] De Smet AA, Ilahi OA, Graf BK. Untreated osteochondritis dissecans of the femoral condyles: prediction of patient outcome using radiographic and MR findings. Skeletal Radiol. 1997;26(8):463-7.

[23] Hughston JC, Hergenroeder PT, Courtenay BG. Osteochondritis dissecans of the femoral condyles. J Bone Joint Surg [Am]. 1984;66(9):1340-8.

[24] Apprich S, Trattnig S, Welsch GH, Noebauer-Huhmann IM, Sokolwski M, Hirschfeld $\mathrm{C}$, et al. Assessment of articular cartilage repair tissue after matrix-associated autologous chondrocyte transplantation or the microfracture technique in the ankle joint using diffusion-weighted imaging at 3 Tesla. Osteoarthritis Cartilage. 2012 Jul;20(7): 703-11.

[25] Saxena A, Eakin C. Articular talar injuries in athletes: results of microfracture and autogenous bone graft. Am J Sports Med. 2007 Oct;35(10):1680-7.

[26] Doral MN, Bilge O, Batmaz G, Donmez G, Turhan E, Demirel M, et al. Treatment of osteochondral lesions of the talus with microfracture technique and postoperative hyaluronan injection. Knee Surg Sports Traumatol Arthrosc. 2012;20:1298-403.

[27] Becher C, Driessen A, Hess T, Longo UG, Maffulli N, Thermann H. Microfracture for chondral defects of the talus: maintenance of early results at midterm follow-up. Knee Surg Sports Traumatol Arthrosc. 2010 May;18(5):656-63.

[28] Brittberg M, Lindahl A, Nilsson A, Ohlsson C, Isaksson O, Peterson L. Treatment of deep cartilage defects in the knee with autologous chondrocyte transplantation. The New England journal of medicine. 1994;331(14):889-95.

[29] Battaglia M, Vannini F, Buda R, Cavallo M, Ruffilli A, Monti C, et al. Arthroscopic autologous chondrocyte implantation in osteochondral lesions of the talus: mid-term T2-mapping MRI evaluation. Knee Surg Sports Traumatol Arthrosc. 2011 Aug;19(8): 1376-84.

[30] Dixon S, Harvey L, Baddour E, Janes G, Hardisty G. Functional outcome of matrixassociated autologous chondrocyte implantation in the ankle. Foot Ankle Int. 2011 Apr;32(4):368-74.

[31] Giza E, Sullivan M, Ocel D, Lundeen G, Mitchell ME, Veris L, et al. Matrix-induced autologous chondrocyte implantation of talus articular defects. Foot Ankle Int. 2010 Sep;31(9):747-53.

[32] Saris DB, Vanlauwe J, Victor J, Haspl M, Bohnsack M, Fortems Y, et al. Characterized chondrocyte implantation results in better structural repair when treating symptomatic cartilage defects of the knee in a randomized controlled trial versus microfracture. Am J Sports Med. 2008 Feb;36(2):235-46.

[33] Liu W, Liu F, Zhao W, Kim JM, Wang Z, Vrahas MS. Osteochondral autograft transplantation for acute osteochondral fractures associated with an ankle fracture. Foot Ankle Int. 2011 Apr;32(4):437-42. 
[34] Gobbi A, Francisco RA, Lubowitz JH, Allegra F, Canata G. Osteochondral lesions of the talus: randomized controlled trial comparing chondroplasty, microfracture, and osteochondral autograft transplantation. Arthroscopy. 2006 Oct;22(10):1085-92.

[35] Valderrabano V, Leumann A, Rasch H, Egelhof T, Hintermann B, Pagenstert G. Knee-to-ankle mosaicplasty for the treatment of osteochondral lesions of the ankle joint. Am J Sports Med. 2009 Nov;37 Suppl 1:105S-11S.

[36] Hangody L, Dobos J, Balo E, Panics G, Hangody LR, Berkes I. Clinical experiences with autologous osteochondral mosaicplasty in an athletic population: a 17-year prospective multicenter study. Am J Sports Med. 2010 Jun;38(6):1125-33.

[37] Hangody L, Kish G, Modis L, Szerb I, Gaspar L, Dioszegi Z, et al. Mosaicplasty for the treatment of osteochondritis dissecans of the talus: two to seven year results in 36 patients. Foot Ankle Int. 2001;22(7):552-8.

[38] El-Rashidy H, Villacis D, Omar I, Kelikian AS. Fresh osteochondral allograft for the treatment of cartilage defects of the talus: a retrospective review. J Bone Joint Surg Am. 2011 Sep 7;93(17):1634-40.

[39] Adams SB, Jr., Viens NA, Easley ME, Stinnett SS, Nunley JA, 2nd. Midterm results of osteochondral lesions of the talar shoulder treated with fresh osteochondral allograft transplantation. J Bone Joint Surg Am. 2011 Apr 6;93(7):648-54.

[40] Aubin PP, Cheah HK, Davis AM, Gross AE. Long-term followup of fresh femoral osteochondral allografts for posttraumatic knee defects. Clin Orthop. 2001(391 Suppl):S318-27.

[41] Tontz WL, Jr., Bugbee WD, Brage ME. Use of allografts in the management of ankle arthritis. Foot Ankle Clin. 2003 Jun;8(2):361-73, xi.

[42] Garcia EJ, Bear RR, Schoenfeld AJ, Owens BD. Treatment of osteochondral lesions of the talus with a biosynthetic scaffold: a report of four cases. J Bone Joint Surg Am. 2010 Jul 21;92(8):1774-9.

[43] Giannini S, Buda R, Vannini F, Cavallo M, Grigolo B. One-step bone marrow-derived cell transplantation in talar osteochondral lesions. Clin Orthop Relat Res. 2009 Dec; 467(12):3307-20.

[44] Barnewitz D, Endres M, Kruger I, Becker A, Zimmermann J, Wilke I, et al. Treatment of articular cartilage defects in horses with polymer-based cartilage tissue engineering grafts. Biomaterials. 2006 May;27(14):2882-9.

[45] Candrian C, Barbero A, Bonacina E, Francioli S, Hirschmann MT, Milz S, et al. A novel implantation technique for engineered osteo-chondral grafts. Knee Surg Sports Traumatol Arthrosc. 2009 Nov;17(11):1377-83.

[46] Lee KB, Bai LB, Yoon TR, Jung ST, Seon JK. Second-look arthroscopic findings and clinical outcomes after microfracture for osteochondral lesions of the talus. Am J Sports Med. 2009 Nov;37 Suppl 1:63S-70S. 
[47] Nam EK, Ferkel RD, Applegate GR. Autologous chondrocyte implantation of the ankle: a 2- to 5-year follow-up. Am J Sports Med. 2009 Feb;37(2):274-84.

[48] Giannini S, Battaglia M, Buda R, Cavallo M, Ruffilli A, Vannini F. Surgical treatment of osteochondral lesions of the talus by open-field autologous chondrocyte implantation: a 10-year follow-up clinical and magnetic resonance imaging T2-mapping evaluation. Am J Sports Med. 2009 Nov;37 Suppl 1:112S-8S.

[49] Matricali GA, Bartels W, Labey L, Dereymaeker GP, Luyten FP, Vander Sloten J. Changes in contact area characteristics of the ankle after a cartilage biopsy at the postero-medial rim of the talar dome. Osteoarthritis Cartilage. 2009 Nov;17(11): 1477-84.

[50] Giannini S, Buda R, Vannini F, Di Caprio F, Grigolo B. Arthroscopic autologous chondrocyte implantation in osteochondral lesions of the talus: surgical technique and results. Am J Sports Med. 2008 May;36(5):873-80.

[51] Schneider TE, Karaikudi S. Matrix-Induced Autologous Chondrocyte Implantation (MACI) grafting for osteochondral lesions of the talus. Foot Ankle Int. 2009 Sep;30(9): 810-4.

[52] Thermann H, Driessen A, Becher C. [Autologous chondrocyte transplantation in the treatment of articular cartilage lesions of the talus]. Der Orthopade. 2008 Mar;37(3): 232-9.

[53] Lim HC, Bae JH, Song SH, Park YE, Kim SJ. Current treatments of isolated articular cartilage lesions of the knee achieve similar outcomes. Clin Orthop Relat Res. 2012 Aug;470(8):2261-7.

[54] Kilic A, Kabukcuoglu Y, Gul M, Ozkaya U, Sokucu S. [Early results of open mosaicplasty in osteochondral lesions of the talus]. Acta orthopaedica et traumatologica turcica. 2009 May-Jul;43(3):235-42.

[55] Reddy S, Pedowitz DI, Parekh SG, Sennett BJ, Okereke E. The morbidity associated with osteochondral harvest from asymptomatic knees for the treatment of osteochondral lesions of the talus. Am J Sports Med. 2007 Jan;35(1):80-5.

[56] Hahn DB, Aanstoos ME, Wilkins RM. Osteochondral lesions of the talus treated with fresh talar allografts. Foot Ankle Int. 2010 Apr;31(4):277-82.

[57] Williams SK, Amiel D, Ball ST, Allen RT, Wong VW, Chen AC, et al. Prolonged storage effects on the articular cartilage of fresh human osteochondral allografts. J Bone Joint Surg Am. 2003 Nov;85-A(11):2111-20.

[58] Ball ST, Amiel D, Williams SK, Tontz W, Chen AC, Sah RL, et al. The effects of storage on fresh human osteochondral allografts. Clin Orthop Relat Res. 2004 Jan(418): 246-52.

[59] Jomha NM, Elliott JA, Law GK, Maghdoori B, Fraser Forbes J, Abazari A, et al. Vitrification of intact human articular cartilage. Biomaterials. 2012 Sep;33(26):6061-8. 
[60] Meehan R, McFarlin S, Bugbee W, Brage M. Fresh ankle osteochondral allograft transplantation for tibiotalar joint arthritis. Foot Ankle Int. 2005 Oct;26(10):793-802.

[61] Giannini S, Buda R, Grigolo B, Bevoni R, Di Caprio F, Ruffilli A, et al. Bipolar fresh osteochondral allograft of the ankle. Foot Ankle Int. 2010 Jan;31(1):38-46.

[62] Bugbee WD, Convery FR. Osteochondral allograft transplantation. Clinics in sports medicine. 1999;18(1):67-75.

[63] Mann HA, Filippi J, Myerson MS. Intra-articular opening medial tibial wedge osteotomy (plafond-plasty) for the treatment of intra-articular varus ankle arthritis and instability. Foot Ankle Int. 2012 Apr;33(4):255-61.

[64] Knupp M, Stufkens SA, van Bergen CJ, Blankevoort L, Bolliger L, van Dijk CN, et al. Effect of supramalleolar varus and valgus deformities on the tibiotalar joint: a cadaveric study. Foot Ankle Int. 2011 Jun;32(6):609-15.

[65] Lee WC, Moon JS, Lee K, Byun WJ, Lee SH. Indications for supramalleolar osteotomy in patients with ankle osteoarthritis and varus deformity. J Bone Joint Surg Am. 2011 Jul 6;93(13):1243-8.

[66] Saltzman CL, Hillis SL, Stolley MP, Anderson DD, Amendola A. Motion versus fixed distraction of the joint in the treatment of ankle osteoarthritis: a prospective randomized controlled trial. J Bone Joint Surg Am. 2012 Jun 6;94(11):961-70.

[67] Albert E. Zur resection des Kniegelenkes. Wein Med Press. 1879;20:705-8.

[68] Hendrickx RP, Stufkens SA, de Bruijn EE, Sierevelt IN, van Dijk CN, Kerkhoffs GM. Medium- to long-term outcome of ankle arthrodesis. Foot Ankle Int. 2011 Oct;32(10): 940-7.

[69] Haddad SL, Coetzee JC, Estok R, Fahrbach K, Banel D, Nalysnyk L. Intermediate and long-term outcomes of total ankle arthroplasty and ankle arthrodesis. A systematic review of the literature. J Bone Joint Surg Am. 2007 Sep;89(9):1899-905.

[70] Crosby LA, Yee TC, Formanek TS, Fitzgibbons TC. Complications following arthroscopic ankle arthrodesis. Foot Ankle Int. 1996 Jun;17(6):340-2.

[71] Cooper PS. Complications of ankle and tibiotalocalcaneal arthrodesis. Clin Orthop Relat Res. 2001 Oct(391):33-44.

[72] Akra GA, Middleton A, Adedapo AO, Port A, Finn P. Outcome of ankle arthrodesis using a transfibular approach. J Foot Ankle Surg. 2010 Nov-Dec;49(6):508-12.

[73] Gessmann J, Ozokyay L, Fehmer T, Muhr G, Seybold D. [Arthrodesis of the infected ankle joint: results with the Ilizarov external fixator]. Zeitschrift fur Orthopadie und Unfallchirurgie. 2011 Apr;149(2):212-8.

[74] Hollawell SM. Allograft cellular bone matrix as an alternative to autograft in hindfoot and ankle fusion procedures. J Foot Ankle Surg. 2012 Mar-Apr;51(2):222-5. 
[75] Guo C, Yan Z, Barfield WR, Hartsock LA. Ankle arthrodesis using anatomically contoured anterior plate. Foot Ankle Int. 2010 Jun;31(6):492-8.

[76] Zwipp H, Rammelt S, Endres T, Heineck J. High union rates and function scores at midterm followup with ankle arthrodesis using a four screw technique. Clin Orthop Relat Res. 2010 Apr;468(4):958-68.

[77] Mohamedean A, Said HG, El-Sharkawi M, El-Adly W, Said GZ. Technique and short-term results of ankle arthrodesis using anterior plating. International orthopaedics. 2010 Aug;34(6):833-7.

[78] Boer R, Mader K, Pennig D, Verheyen CC. Tibiotalocalcaneal arthrodesis using a reamed retrograde locking nail. Clin Orthop Relat Res. 2007 Oct;463:151-6.

[79] Tang KL, Li QH, Chen GX, Guo L, Dai G, Yang L. Arthroscopically assisted ankle fusion in patients with end-stage tuberculosis. Arthroscopy. 2007 Sep;23(9):919-22.

[80] Eylon S, Porat S, Bor N, Leibner ED. Outcome of Ilizarov ankle arthrodesis. Foot Ankle Int. 2007 Aug;28(8):873-9.

[81] Gougoulias NE, Agathangelidis FG, Parsons SW. Arthroscopic ankle arthrodesis. Foot Ankle Int. 2007 Jun;28(6):695-706.

[82] Colman AB, Pomeroy GC. Transfibular ankle arthrodesis with rigid internal fixation: an assessment of outcome. Foot Ankle Int. 2007 Mar;28(3):303-7.

[83] Pelton K, Hofer JK, Thordarson DB. Tibiotalocalcaneal arthrodesis using a dynamically locked retrograde intramedullary nail. Foot Ankle Int. 2006 Oct;27(10):759-63.

[84] Didomenico LA, Sann P. Posterior approach using anterior ankle arthrodesis locking plate for tibiotalocalcaneal arthrodesis. J Foot Ankle Surg. 2011 Sep-Oct;50(5):626-9.

[85] Hanson TW, Cracchiolo A, 3rd. The use of a 95 degree blade plate and a posterior approach to achieve tibiotalocalcaneal arthrodesis. Foot Ankle Int. 2002 Aug;23(8): 704-10.

[86] Nickisch F, Avilucea FR, Beals T, Saltzman C. Open posterior approach for tibiotalar arthrodesis. Foot Ankle Clin. 2011 Mar;16(1):103-14.

[87] Collman DR, Kaas MH, Schuberth JM. Arthroscopic ankle arthrodesis: factors influencing union in 39 consecutive patients. Foot Ankle Int. 2006 Dec;27(12):1079-85.

[88] Cameron SE, Ullrich P. Arthroscopic arthrodesis of the ankle joint. Arthroscopy. 2000 Jan-Feb;16(1):21-6.

[89] Schuh R, Hofstaetter J, Krismer M, Bevoni R, Windhager R, Trnka HJ. Total ankle arthroplasty versus ankle arthrodesis. Comparison of sports, recreational activities and functional outcome. International orthopaedics. 2012 Jun;36(6):1207-14.

[90] Goldberg AJ, Sharp RJ, Cooke P. Ankle replacement: current practice of foot \& ankle surgeons in the United kingdom. Foot Ankle Int. 2009 Oct;30(10):950-4. 
[91] Lord G, Marotte JH. [Total ankle replacement (author's transl)]. Revue de chirurgie orthopedique et reparatrice de l'appareil moteur. 1980 Nov-Dec;66(8):527-30.

[92] Hintermann B, Valderrabano V. Total ankle replacement. Foot Ankle Clin. 2003 Jun; 8(2):375-405.

[93] Bolton-Maggs BG, Sudlow RA, Freeman MA. Total ankle arthroplasty. A long-term review of the London Hospital experience. J Bone Joint Surg Br. 1985 Nov;67(5): 785-90.

[94] Easley ME, Vertullo CJ, Urban WC, Nunley JA. Total ankle arthroplasty. The Journal of the American Academy of Orthopaedic Surgeons. 2002 May-Jun;10(3):157-67.

[95] Kitaoka HB, Patzer GL. Clinical results of the Mayo total ankle arthroplasty. J Bone Joint Surg Am. 1996 Nov;78(11):1658-64.

[96] Hamblen DL. Can the ankle joint be replaced? J Bone Joint Surg Br. 1985 Nov;67(5): 689-90.

[97] Lewis G. Biomechanics of and research challenges in uncemented total ankle replacement. Clin Orthop Relat Res. 2004 Jul(424):89-97.

[98] Hintermann B. Total ankle arthroplasty. St. Stefan, Austria: Springer Wein New York 2005.

[99] Dyrby C, Chou LB, Andriacchi TP, Mann RA. Functional evaluation of the Scandinavian Total Ankle Replacement. Foot Ankle Int. 2004 Jun;25(6):377-81.

[100] Michelson JD, Schmidt GR, Mizel MS. Kinematics of a total arthroplasty of the ankle: comparison to normal ankle motion. Foot Ankle Int. 2000 Apr;21(4):278-84.

[101] Yalamanchili P, Neufeld S, Lin S. Total ankle arthroplasty: A modern perspective. Curr Orthop Prac. 2009;20(2):106-11-.

[102] Neufeld SK, Lee TH. Total ankle arthroplasty: indications, results, and biomechanical rationale. American journal of orthopedics (Belle Mead, NJ. 2000 Aug;29(8):593-602.

[103] Pyevich MT, Saltzman CL, Callaghan JJ, Alvine FG. Total ankle arthroplasty: a unique design. Two to twelve-year follow-up. J Bone Joint Surg Am. 1998 Oct;80(10): 1410-20.

[104] Gould JS, Alvine FG, Mann RA, Sanders RW, Walling AK. Total ankle replacement: a surgical discussion. Part II. The clinical and surgical experience. American journal of orthopedics (Belle Mead, NJ. 2000 Sep;29(9):675-82.

[105] Gould JS, Alvine FG, Mann RA, Sanders RW, Walling AK. Total ankle replacement: a surgical discussion. Part I. Replacement systems, indications, and contraindications. American journal of orthopedics (Belle Mead, NJ. 2000 Aug;29(8):604-9.

[106] Demottaz JD, Mazur JM, Thomas WH, Sledge CB, Simon SR. Clinical study of total ankle replacement with gait analysis. A preliminary report. J Bone Joint Surg Am. 1979 Oct;61(7):976-88. 
[107] Gill LH. Challenges in total ankle arthroplasty. Foot Ankle Int. 2004 Apr;25(4): 195-207.

[108] Inman VT. Inman's joints of the ankle. Baltimore, MD: Williams \& Wilkins 1976.

[109] Sammarco J. Biomechanics of the ankle. I. Surface velocity and instant center of rotation in the sagittal plane. Am J Sports Med. 1977 Nov-Dec;5(6):231-4.

[110] Komistek RD, Stiehl JB, Buechel FF, Northcut EJ, Hajner ME. A determination of ankle kinematics using fluoroscopy. Foot Ankle Int. 2000 Apr;21(4):343-50.

[111] Saltzman CL. Perspective on total ankle replacement. Foot Ankle Clin. 2000 Dec;5(4): 761-75.

[112] Cracchiolo A, 3rd, Deorio JK. Design features of current total ankle replacements: implants and instrumentation. The Journal of the American Academy of Orthopaedic Surgeons. 2008 Sep;16(9):530-40.

[113] Chou LB, Coughlin MT, Hansen S, Jr., Haskell A, Lundeen G, Saltzman CL, et al. Osteoarthritis of the ankle: the role of arthroplasty. The Journal of the American Academy of Orthopaedic Surgeons. 2008 May;16(5):249-59.

[114] Cenni F, Leardini A, Belvedere C, Bugane F, Cremonini K, Miscione MT, et al. Kinematics of the three components of a total ankle replacement: in vivo fluoroscopic analysis. Foot Ankle Int. 2012 Apr;33(4):290-300.

[115] Brodsky JW, Polo FE, Coleman SC, Bruck N. Changes in gait following the Scandinavian Total Ankle Replacement. J Bone Joint Surg Am. 2011 Oct 19;93(20):1890-6.

[116] Barnett $\mathrm{CH}$, Napier JR. The axis of rotation at the ankle joint in man; its influence upon the form of the talus and the mobility of the fibula. Journal of anatomy. 1952 Jan;86(1):1-9.

[117] Newton SE, 3rd. Total ankle arthroplasty. Clinical study of fifty cases. J Bone Joint Surg Am. 1982 Jan;64(1):104-11.

[118] Conti SF, Wong YS. Complications of total ankle replacement. Foot Ankle Clin. 2002 Dec;7(4):791-807, vii.

[119] Raikin SM, Kane J, Ciminiello ME. Risk factors for incision-healing complications following total ankle arthroplasty. J Bone Joint Surg Am. 2010 Sep 15;92(12):2150-5.

[120] Kobayashi A, Minoda Y, Kadoya Y, Ohashi H, Takaoka K, Saltzman CL. Ankle arthroplasties generate wear particles similar to knee arthroplasties. Clin Orthop Relat Res. 2004 Jul(424):69-72.

[121] Conti S, Lalonde KA, Martin R. Kinematic analysis of the agility total ankle during gait. Foot Ankle Int. 2006 Nov;27(11):980-4.

[122] Barg A, Knupp M, Anderson AE, Hintermann B. Total ankle replacement in obese patients: component stability, weight change, and functional outcome in 118 consecutive patients. Foot Ankle Int. 2011 Oct;32(10):925-32. 
[123] Cornelis Doets H, van der Plaat LW, Klein JP. Medial malleolar osteotomy for the correction of varus deformity during total ankle arthroplasty: results in 15 ankles. Foot Ankle Int. 2008 Feb;29(2):171-7.

[124] Reddy SC, Mann JA, Mann RA, Mangold DR. Correction of moderate to severe coronal plane deformity with the STAR ankle prosthesis. Foot Ankle Int. 2011 Jul;32(7): 659-64.

[125] Shock RP, Christensen JC, Schuberth JM. Total ankle replacement in the varus ankle. J Foot Ankle Surg. 2011 Jan-Feb;50(1):5-10.

[126] Ryssman DB, Myerson MS. Total ankle arthroplasty: management of varus deformity at the ankle. Foot Ankle Int. 2012 Apr;33(4):347-54.

[127] Barg A, Henninger HB, Hintermann B. Risk factors for symptomatic deep-vein thrombosis in patients after total ankle replacement who received routine chemical thromboprophylaxis. J Bone Joint Surg Br. 2011 Jul;93(7):921-7.

[128] Bestic JM, Peterson JJ, DeOrio JK, Bancroft LW, Berquist TH, Kransdorf MJ. Postoperative evaluation of the total ankle arthroplasty. Ajr. 2008 Apr;190(4):1112-23.

[129] Fevang BT, Lie SA, Havelin LI, Brun JG, Skredderstuen A, Furnes O. 257 ankle arthroplasties performed in Norway between 1994 and 2005. Acta orthopaedica. 2007 Oct;78(5):575-83.

[130] Hosman AH, Mason RB, Hobbs T, Rothwell AG. A New Zealand national joint registry review of 202 total ankle replacements followed for up to 6 years. Acta orthopaedica. 2007 Oct;78(5):584-91.

[131] Skytta ET, Koivu H, Eskelinen A, Ikavalko M, Paavolainen P, Remes V. Total ankle replacement: a population-based study of 515 cases from the Finnish Arthroplasty Register. Acta orthopaedica. 2010 Feb;81(1):114-8.

[132] Henricson A, Nilsson JA, Carlsson A. 10-year survival of total ankle arthroplasties: a report on 780 cases from the Swedish Ankle Register. Acta orthopaedica. 2011 Dec; 82(6):655-9.

[133] Labek G, Klaus H, Schlichtherle R, Williams A, Agreiter M. Revision rates after total ankle arthroplasty in sample-based clinical studies and national registries. Foot Ankle Int. 2011 Aug;32(8):740-5.

[134] Gougoulias N, Khanna A, Maffulli N. How successful are current ankle replacements?: a systematic review of the literature. Clin Orthop Relat Res. 2010 Jan;468(1): 199-208.

[135] Stengel D, Bauwens K, Ekkernkamp A, Cramer J. Efficacy of total ankle replacement with meniscal-bearing devices: a systematic review and meta-analysis. Arch Orthop Trauma Surg. 2005 Mar;125(2):109-19.

[136] Mann JA, Mann RA, Horton E. STAR ankle: long-term results. Foot Ankle Int. 2011 May;32(5):S473-84. 
[137] Bonnin M, Gaudot F, Laurent JR, Ellis S, Colombier JA, Judet T. The Salto total ankle arthroplasty: survivorship and analysis of failures at 7 to 11 years. Clin Orthop Relat Res. 2011 Jan;469(1):225-36.

[138] Wood PL, Sutton C, Mishra V, Suneja R. A randomised, controlled trial of two mobile-bearing total ankle replacements. J Bone Joint Surg Br. 2009 Jan;91(1):69-74.

[139] Hahn ME, Wright ES, Segal AD, Orendurff MS, Ledoux WR, Sangeorzan BJ. Comparative gait analysis of ankle arthrodesis and arthroplasty: initial findings of a prospective study. Foot Ankle Int. 2012 Apr;33(4):282-9.

[140] Piriou P, Culpan P, Mullins M, Cardon JN, Pozzi D, Judet T. Ankle replacement versus arthrodesis: a comparative gait analysis study. Foot Ankle Int. 2008 Jan;29(1):3-9.

[141] Penner MJ, Pakzad H, Younger A, Wing KJ. Mean BMI of overweight and obese patients does not decrease after successful ankle reconstruction. J Bone Joint Surg Am. 2012 May 2;94(9):e57. 
